\title{
WHEN STAYING IS DISSATISFYING: EXAMINING WHEN AND WHY TURNOVER COGNITIONS AFFECT STAYERS' CAREER SATISFACTION
}

\author{
Marijke Verbruggen \\ KU Leuven \\ Hetty van Emmerik \\ Maastricht University
}

Acknowledgements: The authors would like to thank Anneleen Forrier, Maddy Janssens, Lynn Germeys, Joni Delanoeije and Drew Mallory as well as the anonymous reviewers of Journal of Management for their valuable feedback on earlier versions of the manuscript and Ellen Peeters, Jill Nelissen, Nele De Cuyper, Anneleen Forrier and Hans De Witte for help with the part of the data collection. Part of this research was supported by the Research Fund KU Leuven under Grant OT/11/010, by the Research Foundation - Flanders under Grant FWO G.0987.12 and by the EOS Grant CARST G0E8318N.

Corresponding author: Marijke Verbruggen, Department of Work and Organisation Studies, Faculty of Economics and Business, KU Leuven, Naamsestraat 69, 3000 Leuven, BELGIUM E-mail: Marijke.Verbruggen@kuleuven.be 
WHEN STAYING IS DISSATISFYING

This study examines when and why turnover cognitions affect stayers' subsequent career satisfaction. To develop our hypotheses, we build on and compare two theoretical perspectives, i.e., the insufficient justification perspective and regret theory. Hypotheses were tested using two studies with Belgian employees. The baseline hypothesis that initial turnover cognitions are related with lower subsequent career satisfaction received support in both studies. In Study 1, using two-wave data from 226 employees in four organizations, we tested whether the turnover cognitions-subsequent career satisfaction relationship was moderated by four contextual factors (i.e., internal job transitions, lack of external job opportunities, on-thejob embeddedness and off-the-job embeddedness). We found marginal support for a mitigating role of internal job transitions, support for a mitigating role of lack of external job opportunities and support for an amplifying role of off-the-job embeddedness. We found no moderation effect of on-the-job embeddedness. In Study 2, using three-wave information from 705 employees in seven organizations, we tested and found support for the mediating role of justifiability and regret. Overall, this study shows that turnover cognitions have consequences when people end up staying in their organization, which calls for more theoretical and empirical work on staying despite preceding turnover cognitions in order to improve our understanding of the complexity and dynamic nature of the turnover/retention phenomenon.

Keywords: turnover cognitions; career satisfaction; justifiability; regret 
WHEN STAYING IS DISSATISFYING

\section{WHEN STAYING IS DISSATISFYING: EXAMINING WHEN AND WHY TURNOVER COGNITIONS AFFECT STAYERS' CAREER SATISFACTION}

Turnover cognitions are among the most popular research topics in the fields of management and organizational behavior (Chen, Ployhart, Thomas, Anderson, \& Bliese, 2011). Most studies on turnover cognitions have examined antecedents of turnover cognitions (Hom, 2011; Podsakoff, LePine, \& LePine, 2007; Zimmerman, 2008), revealing job satisfaction, organizational commitment, shock events, and job embeddedness as the most important predictors of turnover thoughts (Jiang, Liu, McKay, Lee, \& Mitchell, 2012; Niederman, Sumner, Maertz, \& Carl, 2007); or they investigated the predictive value of turnover cognitions for actual turnover (Hom, 2011; Podsakoff et al., 2007; Zimmerman, 2008). Much less research has been done on outcomes of turnover cognitions for people who end up staying in their organization (Burton, Holtom, Sablynski, Mitchell, \& Lee, 2010; Mai, Ellis, Christian, \& Porter, 2016). This is surprising since many people who have turnover thoughts at a certain point in time have not left their employer one to two years later (Allen, Weeks, \& Moffitt, 2005; Vardaman, Allen, Renn, \& Moffitt, 2008). Several authors have pointed to this group of stayers - using labels like "intention-to-quit nonquitters" (Bowen, 1982), "psychological quits" (Greenhalgh, 1980), and "reluctant stayers” (Hom, Mitchell, Lee, \& Griffeth, 2012) - and hinted at potential outcomes initial turnover cognitions may induce among this group of stayers (Bowen, 1982; Greenhalgh, 1980).

The few empirical studies that examined outcomes of turnover cognitions for stayers have focused on behavioral outcomes. These studies found that employees who stayed in their organization despite preceding turnover thoughts showed on average lower job performance (Burton et al., 2010), fewer organizational citizenship behaviors (Burris, Detert, \& Chiaburu, 2008; Burton et al., 2010; Holtom, Burton, \& Crossley, 2012; Mai et al., 2016), and more deviance behaviors (Holtom et al., 2012; Mai et al., 2016). However, since most of these 


\section{WHEN STAYING IS DISSATISFYING}

studies used short timeframes of only a couple of weeks (i.e., Burris et al., 2008; Burton et al., 2010; Mai et al., 2016), it could be that instead of turnover cognitions inducing these behavioral outcomes, these behaviors co-occur with turnover cognitions in response to an underlying detachment process induced by third factors, such as job or pay dissatisfaction, a shock event, bad health, or family-related reasons (cf. Hom et al., 2012; Maertz \& Kmitta, 2012). In addition, given the short timeframes, it is also likely that these behaviors are actually "pre-quitting behaviors" and, thus, that these employees will still leave the organization in the short run (Gardner, Van Iddekinge, \& Hom, 2016). Consequently, overall, we do not know much about outcomes of turnover cognitions for stayers in the longer run.

We argue that to improve our understanding of this issue, we need to better understand the internal processes that are triggered by turnover cognitions when people end up staying in the organization. A recent qualitative study by Rothausen and colleagues (2017) indeed showed that when people consider leaving their organization, several internal (e.g., cognitive, emotional) processes are set in motion, which exist in complex interrelationships and that can produce outcomes among stayers (and leavers) in the longer run. These authors further argued that more insight into these processes in employees is crucial for managers to adequately address any deleterious outcomes of unrealized turnover thoughts and to optimize retention management strategies accordingly (Rothausen et al., 2017).

The aim of this article is therefore to shed light on the internal processes that are triggered by initial turnover cognitions and that can produce outcomes among stayers in the longer run. We do so by examining under which conditions (study 1) and through which mechanisms (study 2) initial turnover cognitions are related with stayers' subsequent career satisfaction. Rothausen and colleagues (2017) showed that studying turnover as a wellbeing process can reveal important internal processes that affect outcomes among stayers in the longer run. Therefore, a satisfaction outcome is likely to be well suited to unravel the internal 
WHEN STAYING IS DISSATISFYING

processes triggered by turnover cognitions. We focus specifically on career satisfaction, that is, people's satisfaction with how their career evolves and progresses over time (Greenhaus, Parasuraman, \& Wormley, 1990; Verbruggen, Sels, \& Forrier, 2007), since this wellbeing indicator is not confined to one job or one organization (Heslin, 2005). This is particularly relevant for our research since turnover cognitions concern considerations of leaving the current organization for another one - and thus considerations of a career path that crosses organizational boundaries.

To reveal internal processes induced by initial turnover cognitions, we build on and compare two theoretical perspectives: the insufficient justification perspective (Salancik \& Pfeffer, 1978) and regret theory (Zeelenberg \& Pieters, 2007). Justifiability and regret are considered to be two of the most important internal factors affecting people's decision making and their subsequent satisfaction (Bettman, Luce, \& Payne, 1998; Heitmann, Lehmann, \& Herrmann, 2007; Luce, Bettman, \& Payne, 2001); however, they have received hardly any research attention in the turnover literature to date (although justifiability has been mentioned occasionally, e.g., Burton et al., 2010). As we will explain further, both the justifiability and the regret perspectives suggest that initial turnover cognitions are likely to reduce stayers' subsequent career satisfaction and that contextual factors which can explain the turnover cognitions-turnover gap play an important moderating role. However, the two perspectives do not fully agree about the nature of this moderating effect, and they put forward different explanatory mechanisms (i.e., insufficient justifiability versus regret). Comparing predictions based on both perspectives can therefore shed light on the relative importance of these perspectives in a turnover context and may help to improve our understanding of when and why turnover cognitions produce outcomes among stayers.

We conducted two studies, both spanning one year, to test our hypotheses. In the first, two-wave study with 242 employees, we examined whether the relationship between stayers' 


\section{WHEN STAYING IS DISSATISFYING}

initial turnover cognitions and their subsequent career satisfaction is moderated by internal job transitions, lack of external job opportunities, on-the-job and off-the-job embeddedness. These four contextual factors are regularly put forward as explanations for the turnover cognitions-turnover gap (Hausknecht, Rodda, \& Howard, 2009; Mitchell, Holtom, Lee, Sablynski, \& Erez, 2001) and may therefore, according to both the insufficient justification and the regret perspectives, play an important moderating role. In the second, three-wave study with 705 employees, we tested the mediating role of insufficient justifiability and regret.

This article makes several contributions to the literature. First, we expand the theoretical understanding of the impact of turnover cognitions among stayers by integrating insights from the insufficient justification perspective and regret theory with insights from turnover research. In doing so, our research helps to explain when and why turnover cognitions can produce outcomes among stayers in the longer run. Second, we challenge the predominant assumption in the turnover literature that dissatisfaction induces turnover thoughts by studying the reversed relationship, that is, the effect of initial turnover cognitions on stayers' subsequent career satisfaction. Third, we apply a dynamic perspective to career satisfaction by examining what affects career satisfaction over time, through which mechanisms, and under which conditions. Although there is significant agreement that career satisfaction is a dynamic construct, many empirical studies have examined static models of career satisfaction and thus failed to capture its dynamic nature (Spurk \& Abele, 2014; e.g., Colakoglu, 2011; Verbruggen, 2012; Wolff \& Moser, 2009). Fourth, by examining the moderating impact of internal job transitions, lack of external job opportunities, and two types of job embeddedness, we expand the nomological network of these variables, which are generally modeled as antecedents of turnover (e.g., Niederman et al., 2007).

THEORETICAL FOUNDATIONS AND HYPOTHESES DEVELOPMENT

\section{Turnover Cognitions among Stayers}


WHEN STAYING IS DISSATISFYING

Turnover cognitions refer to the extent to which employees consider leaving their organization. These cognitions typically include thinking about leaving, intending to search for a new job, and intending to leave the organization (Mobley, 1977). Turnover cognitions have been included in almost all theories, models, and empirical studies on turnover (Hom, Lee, Shaw, \& Hausknecht, 2017; Zimmerman, 2008). This has resulted in consistent yet rather moderate support for the turnover cognitions-turnover relationship: turnover cognitions have been found to explain only $10 \%$ to $20 \%$ of the variance in actual turnover (Allen et al., 2005; Vardaman et al., 2008), and most employees with turnover cognitions end up staying with their employer (Allen et al., 2005; Griffeth, Hom, \& Gaertner, 2000). Though researchers have long recognized this turnover cognitions-turnover gap (Greenhalgh, 1980; Bowen, 1982), only a limited number of studies has focused on understanding it. Existing studies either examined explanations for the gap or reflected on its potential consequences (Mai et al., 2016; Vardaman et al., 2008).

The researchers that examined explanations for the turnover cognitions-turnover gap have mainly pointed to the role of contextual factors (Bowen, 1982; Greenhalgh, 1980; Swider, Boswell, \& Zimmerman, 2011). These contextual explanations have been categorized as opportunities and dependencies (Greenhalgh, 1980). Opportunities refer to explanations related to the availability of alternative jobs within or outside the organization, whereas dependencies — or job embeddedness (Mitchell et al., 2001) — refer to forces on-the-job (e.g., having a good salary) and off-the-job (e.g., having kids) that keep employees in the organization even when external job opportunities are present (Greenhalgh, 1980; Mitchell et al., 2001). Empirical studies have shown that employees with turnover cognitions are indeed less likely to leave when they receive an internal job opportunity (Carson, Carson, Griffeth, \& Steel, 1994; Dalton \& Todor, 1987), when there are only few external job opportunities available (Gerhart, 1990; Swider et al., 2011), and when there are high perceived costs of 
WHEN STAYING IS DISSATISFYING

leaving (Swider et al., 2011; Vardaman et al., 2008). In addition to these contextual factors, personality traits such as risk aversion and self-monitoring have also been found to play a role (Allen et al., 2005; Vardaman et al., 2008).

A few other researchers have reflected on the potential consequences of turnover cognitions for stayers. The expected consequences include lowered satisfaction (Mowday, Porter, \& Steers, 1982), reduced in-role and extra-role performance (Burris et al., 2008; Burton et al., 2010; Greenhalgh, 1980; Hom et al., 2012; Mai et al., 2016), absenteeism (Bowen, 1982; Greenhalgh, 1980), and more deviance behaviors (Holtom et al., 2012; Hom et al., 2012; Mai et al., 2016). Three main arguments have been put forward to explain these responses. First, it has been argued that some of the behavioral responses are functional equivalents to turnover (Bowen, 1982; Hulin, Roznowski, \& Hachiya, 1985). Turnover and absenteeism, for instance, can both be ways to better fulfill non-work roles or to escape a dissatisfying job (Bowen, 1982). If turnover is not possible, employees may opt for another behavior that serves the same purpose (Hulin et al., 1985). Second, some of the outcomes above may be responses to issues underlying people's turnover cognitions, such as a dissatisfying job or a shock event (Bowen, 1982; Burton et al., 2010; Holtom et al., 2012; Hom et al., 2012; Mai et al., 2016). Burton and colleagues (Burton et al., 2010; Holtom et al., 2012), for instance, argued that stayers may change their behavior after a negative shock in response to the felt injustice due to this negative shock (Burton et al., 2010; Holtom et al., 2012). Third, some authors argue that turnover cognitions initiate a detachment process from the organization, a process which then lowers the expected utility and valence of certain work behaviors, such as extra-role performance (Burris et al., 2008; Mai et al., 2016).

Note that the first two arguments link the expected outcomes of turnover cognitions to factors underlying people's turnover cognitions rather than to the turnover cognitions themselves. Only the latter argument starts from the internal processes induced by turnover 


\section{WHEN STAYING IS DISSATISFYING}

cognitions. Yet, since the studies using this latter explanation (Burris et al., 2008; Mai et al., 2016) used rather short timeframes, it is still possible that also in these studies, the turnover cognitions-performance relationship is due to third factors underlying the detachment process. Consequently, overall, little is known about the internal processes induced by turnover cognitions that can trigger outcomes among stayers in the longer run.

\section{Turnover Cognitions and Stayers' Subsequent Career Satisfaction}

This article aims to extend the understanding of the internal processes induced by turnover cognitions that affect outcomes among stayers in the longer run by examining under which conditions and through which mechanisms turnover cognitions are related with career satisfaction. Career satisfaction is one of the most important indicators of subjective career success (Heslin, 2005) and has been associated both with organizational outcomes, such as organizational commitment and support for organizational change (Carson, Carson, Phillips, \& Roe, 1996; Gaertner, 1989), and individual benefits, such as enhanced wellbeing and quality of life (Abele \& Spurk, 2009; Verbruggen \& Sels, 2010). Career satisfaction is a particular relevant outcome in this respect since it is a dynamic attitude that evolves over time depending on people's career paths and the progress they make toward their intentions and goals (Dries, Pepermans, \& Carlier, 2008; Savickas, 2005). Since employees who thought about changing employers but ended up staying did not realize their preceding turnover cognitions, they may experience lower career satisfaction. There is indeed some research linking turnover cognitions with career satisfaction among stayers, showing support for a negative relationship (e.g., Igbaria \& Greenhaus, 1992; Nauta, Van Vianen, Van der Heijden, Van Dam, \& Willemsen, 2009); yet, these studies were cross-sectional in nature, and turnover cognitions were typically modeled as the outcome variable.

Building on this past cross-sectional research and on the argument that turnover cognitions trigger certain internal processes (Mai et al., 2016; Rothausen et al., 2017), we 


\section{WHEN STAYING IS DISSATISFYING}

expect that turnover cognitions affect stayers' career satisfaction in a negative way via two internal processes - justifiability and regret. Interestingly, each process has a different focus. Whereas the justifiability argument explains dissatisfaction by focusing on the factual situation (i.e., having stayed despite preceding turnover cognitions), the regret argument explains dissatisfaction as arising from counterfactual thoughts about "what could have been." More insight into the role and relative importance of these two processes may better equip organizations and counselors to deal with undesirable outcomes of unrealized turnover thoughts. Below, we explain each of these processes and formulate our hypotheses.

Insufficient justification perspective. Much research has shown that people have a strong need to justify themselves and their actions (Festinger, 1957; Salancik \& Pfeffer, 1978; Tetlock, 1985). This need to justify one's actions is a core element of several psychological and decision-making theories, such as the social-information processing approach (Salancik \& Pfeffer, 1978), cognitive dissonance theory (Festinger, 1958), and reason-based analysis (Shafir, Simonson, \& Tversky 1993). It reflects a desire to enhance one's self-esteem (Hall \& Lindzey, 1978) and to maintain the approval and respect of others (Tetlock, 1985). Not being able to justify one's actions tends to create discomfort and to induce dissatisfaction (Bettman et al., 1998; Heitmann et al., 2007).

In most situations, keeping the status quo (like staying in your organization) is the most normal course of action and is the easiest to justify (Connolly \& Zeelenberg, 2002; Inman \& Zeelenberg, 2002). However, the more people think about changing, the more the intended change becomes the expected and most normal way to go (Pieters \& Zeelenberg, 2005). Not realizing this change may then be experienced as abnormal and may therefore feel hard to justify (Heitmann et al., 2007; Inman \& Zeelenberg, 2002). As low justifiability hinders people's innate need to justify themselves and their actions (Salancik \& Pfeffer, 1978; Heitmann et al., 2007), it tends to generate negative affective reactions, such as dissatisfaction 


\section{WHEN STAYING IS DISSATISFYING}

(Bettman et al., 1998). Research has indeed found that when people find it hard to justify a decision in a certain life domain, they are on average less satisfied with that life domain (Heitmann et al., 2007). This is also in line with the study by Rothausen and colleagues (2017), which showed that difficulties in explaining why one stayed in the organization could pose a threat to people's wellbeing. Accordingly, we expect that stayers with stronger initial turnover cognitions are likely to find it more difficult to justify their staying in the organization, which may in turn negatively affect their career satisfaction.

Regret theory. Regret offers a second process that can explain why initial turnover cognitions affect stayers' subsequent career satisfaction. Regret is among the most intense and most frequently occurring negative emotions (Zeelenberg \& Pieters, 2007) and has been investigated in many disciplines, including economic psychology, health psychology, marketing, and organizational behavior (Zeelenberg \& Pieters, 2007). Insights from these disciplines have been integrated in Zeelenberg and Pieter's (2007) theory of regret regulation. Regret can be defined as a negative cognitive emotion which originates from a comparison between what is and what might have been (Chua, Gonzalez, Taylor, Welsh, \& Liberzon, 2009). It is the emotion we feel when we imagine or realize that our current situation could have been better if only we had acted differently (Zeelenberg \& Pieters, 2007). Thus, regret has a strong component of self-blame to it (Zeelenberg, Van Dijk, \& Manstead, 1998).

Regret typically arises when people explored different options or considered making a change. When people think about making a change (here: leaving the organization), they tend to engage in prefactual thinking, meaning that they fantasize about, or construct a mental representation of, what the change would be like (Carmon, Wertenbroch, \& Zeelenberg, 2003; Rothausen et al., 2017). The more a person thinks about and desires a certain alternative, the more positive, vivid, and intense this representation is likely to be and the longer it remains cognitively available. When people then do not actualize the desired change, these prefactual 


\section{WHEN STAYING IS DISSATISFYING}

thoughts tend to evolve into counterfactual thoughts. In other words, thoughts about "what could have been" if they would have realized the desired change (McCloy \& Byrne, 2000; Roese, 1997). When such counterfactual thoughts keep confronting people with what could have been, they can induce regret (Chua et al., 2009; Medvec, Madey, \& Gilovich, 1995; Pieters \& Zeelenberg, 2005). Feelings of regret, in turn, stimulate people to re-evaluate their situation and the corresponding life domain (in this case, their career) in an increasingly negative way, resulting in lowered satisfaction with that life domain (Bullens, van Harreveld, \& Förster, 2011; Kahneman, 1999; Naquin, 2003). This is particularly likely in the career sphere since people are increasingly held responsible for their own career successes and failures (van Vianen, De Pater, \& Preenen, 2009) and, accordingly, increasingly derive career (dis)satisfaction from (un)successfully steering their own career (Verbruggen \& Sels, 2010).

Building on these two arguments, we hypothesize the following:

Hypothesis 1: Stayers' initial turnover cognitions are negatively related with their subsequent career satisfaction.

Hypothesis 2: The relationship between stayers' initial turnover cognitions and their subsequent career satisfaction occurs through (1) difficulties with justifying their staying with their employer and (2) regret about not having left their employer. That is, the stronger people's initial turnover cognitions, the more difficult it will feel to justify having stayed with their employer, and the more regret they will experience about not having left, which will in turn lower their subsequent career satisfaction.

\section{Internal Job Transitions, External Job Opportunities, and Job Embeddedness}

Both the insufficient justification literature and regret research suggest that contextual factors that can explain why people stay with their employer may moderate the relationship between turnover cognitions and stayers' subsequent career satisfaction (Connolly \& Zeelenberg, 2002; Salancik \& Pfeffer, 1978). The insufficient justification literature suggests 


\section{WHEN STAYING IS DISSATISFYING}

that the presence of both opportunities and dependencies may help to justify not having changed employers and could therefore mitigate the turnover cognitions-career satisfaction relationship (Bettman et al., 1998; Heitmann et al., 2007). Regret theory, on the other hand, suggests that only opportunities play a mitigating role since they help to bring closure and stop counterfactual thoughts. In the case of dependencies, however, the opportunity to change remains possible. This may hinder psychological closure, reinforce self-blame, and intensify regret (Beike, Markman, \& Karadogan, 2009) and could therefore strengthen the negative turnover cognitions-subsequent career satisfaction relationship (Hafner, White, \& Handley, 2012; Naquin, 2003). To test and compare both perspectives, we examine the moderating role of two opportunity-related explanations for staying (i.e., having made an internal job transition and a lack of external job opportunities) as well as two dependency-related explanations (i.e., on-the-job and off-the-job embeddedness).

Internal job transitions. Internal job transitions refer to intra-organizational job changes, such as promotions and lateral job changes (Ng, Sorensen, Eby, \& Feldman, 2007). Making an internal job transition can be considered as a form of job turnover, and, accordingly, these transitions have been incorporated in several theoretical turnover models as an alternative to organizational turnover (Steel \& Landon, 2010; e.g., March \& Simon, 1958). This has been supported by empirical research, which has found that employees who made an internal job transition are less likely to leave their organization (Carson et al., 1994; Dalton \& Todor, 1987). In this study, we expect that for employees who made an internal job transition, the relationship between their initial turnover cognitions and their subsequent career satisfaction will be less (or not) negative because having made an internal job transition helps to justify having stayed despite initial turnover cognitions (cf. insufficient justification perspective) and to find closure and experience less regret about not having left (cf. regret perspective). We explain these two lines of reasoning in more detail below. 


\section{WHEN STAYING IS DISSATISFYING}

First, since internal job transitions are often seen as a good and valuable alternative to organizational turnover (Dalton \& Todor, 1987; Steel \& Landon, 2010), having made such a transition is likely to be an easy and convincing argument to explain and justify having stayed in the organization in defiance of earlier turnover cognitions. Since employees who made an internal job transition have a legitimate justification for not having realized their initial turnover cognitions, the inconsistency between their initial turnover cognitions and their current career situation is likely to feel less painful, and, accordingly, they may experience less career dissatisfaction (Heitmann et al., 2007; Tetlock, 1985). So, building on the insufficient justification lens, we expect that the initial turnover cognitions-subsequent career satisfaction relationship is likely to be less negative in the case of an internal job transition.

Second, since an internal job transition is a form of job turnover, it can address several of the reasons underlying people's turnover cognitions (Dalton \& Todor, 1987; Hulin et al., 1985); for instance, just like a transition to another organization, internal job transitions may provide employees with a new challenge, a new working environment, and/or new job responsibilities (Dalton \& Todor, 1987). Accordingly, an internal job transition can help employees to find psychological closure and stop counterfactual thoughts and, thus, to experience less regret about not having left despite initial turnover cognitions (Chua et al., 2009; Medvec et al., 1995). When people have less regret about not having left, they are likely to be less dissatisfied about their career (Bullens et al., 2011; Naquin, 2003). Thus, the regret perspective also suggests that the turnover cognitions-subsequent career satisfaction relationship is likely to be less negative when people have made an internal job transition.

Hypothesis 3: Internal job transitions moderate the relationship between stayers' initial turnover cognitions and their subsequent career satisfaction in the sense that this relationship is less negative when the stayer made an internal job transition.

Lack of external job opportunities. Next, we expect a less negative turnover 


\section{WHEN STAYING IS DISSATISFYING}

cognitions-subsequent career satisfaction relationship when there is a lack of external job opportunities-thus, when the unemployment rate is high—because a high unemployment rate can help stayers to both justify having stayed despite initial turnover cognitions (cf. insufficient justification perspective) and find closure and have less regret about not having left (cf. regret perspective). First, when the unemployment rate is high, it is objectively harder to change organizations (Clark, 2003; Cornelißen, Hübler, \& Schneck, 2007), and, therefore, staying with one's employer even if one wanted otherwise is easier to justify to others (Pfeffer \& Lawler, 1980). As staying despite preceding turnover cognitions is then easier to justify, the turnover cognitions-turnover inconsistency is likely to induce less dissatisfaction compared to a situation with a low unemployment rate (Heitmann et al., 2007; Pfeffer \& Lawler, 1980). Second, when there are only limited job opportunities available, it is highly likely that people who leave their organization will be at least temporarily unemployed (Cornelißen et al., 2007). This awareness could help people to accept the situation as it is and stop fantasizing about what could have been if they had left their organization (Beike et al., 2009). Regret research has indeed shown that people can more easily find closure and stop counterfactual thoughts, and are thus likely to experience less regret, when opportunities are limited in number (Hafner et al., 2012; Naquin, 2003). So, people who end up staying at a job despite preceding turnover cognitions are likely to feel less regret and may therefore be less dissatisfied with their career when the unemployment rate is high compared to a situation with a low unemployment rate (Bullens et al., 2011; Naquin, 2003). This all suggests that a lack of external job opportunities mitigates the negative turnover cognitions-subsequent career satisfaction relationship.

Hypothesis 4: A lack of external job opportunities moderates the relationship between stayers' initial turnover cognitions and their subsequent career satisfaction in the sense that this relationship is less negative when external job opportunities are limited. 
WHEN STAYING IS DISSATISFYING

On-the-job and off-the-job embeddedness. Job embeddedness refers to the extent of an employee's "stuckness" or enmeshment in his or her organization (Lee, Burch, \& Mitchell, 2014). This stuckness can result from different forces in either the organization (on-the-job embeddedness) or the community (off-the-job embeddedness), including how they fit in their organization or community (fit), the links employees have to other people or groups in their organization or community (links), and what they would sacrifice if they were to leave (sacrifices) (Mitchell et al., 2001). These different forces are conceptualized as a web that is attached to - and therefore hard to separate from - their specific context (Mitchell et al., 2001; Lee et al., 2014). In line with this web-metaphor, scholars generally focus on the overall level of on-the-job and off-the-job embeddedness rather than on the separate elements forming this web (Lee et al., 2014). In this article, we follow this approach.

On-the-job and off-the-job embeddedness are dependency-related explanations for staying since they concern external forces that keep employees from leaving the organization even when external job opportunities are available (Mitchell et al., 2001; Lee et al., 2014). The moderating role of dependency explanations is particularly interesting to explore because both a mitigating and a strengthening role are theoretically plausible depending on the perspective that is applied, that is, the insufficient justification paradigm versus regret theory.

On one hand, highly on-the-job and off-the-job embedded employees may be well able to justify to others that they stayed with their employer because of their good organizational and community benefits (Pfeffer \& Lawler, 1980). Research has, for instance, shown that employees regularly use arguments related to both on-the-job embeddedness (e.g., a fitting job, nice colleagues, or a good pension plan) and off-the-job embeddedness (e.g., having kids or being involved in the community) to explain why they did not leave the organizations, even despite preceding turnover thoughts (Donnelly \& Quirin, 2006; Rothausen et al., 2007; Westaby, 2005; Woo \& Allen, 2014). Accordingly, it could be expected that high levels of 


\section{WHEN STAYING IS DISSATISFYING}

on-the-job and off-the-job embeddedness facilitate justifying that one stayed with one's employer. Building on the insufficient justification perspective, we would thus expect a less negative turnover cognitions-subsequent career satisfaction relationship in cases of high onthe-job and high off-the-job embeddedness.

On the other hand, however, highly embedded employees who-despite their embeddedness - desired and intended to leave their employer may experience more regret when they do not eventually leave the organization. As highly embedded individuals tend to stay with their employer because they are stuck in either their organization or community (Mitchell et al., 2001) rather than because there are no job opportunities available, the option to leave the organization generally remains available and relevant. This typically makes it hard to stop fantasizing about the option to leave and to find psychological closure (Beike et al., 2009). People in such situations therefore often keep ruminating about the option to leave and experience more regret. Research has indeed found that when an option remains available and relevant, people tend to experience more regret (Beike et al., 2009), which in turn strengthens their dissatisfaction (Bullens et al., 2011). In addition, when people stay because they feel stuck, they could have implemented their cognitions, and, therefore, they may put the locus of responsibility for their turnover cognitions-turnover inconsistency with themselves and experience more self-blame. This could additionally induce regret about not having made the change (Connolly \& Zeelenberg, 2002). Building on the above, we propose the following alternative hypotheses, one based on the insufficient justification perspective (hypothesis 5) and one based on regret theory (hypothesis 5'):

Hypothesis 5: On-the-job embeddedness (5a) and off-the-job embeddedness (5b) mitigate the relationship between stayers' initial turnover cognitions and their subsequent career satisfaction in the sense that this relationship is less negative if people are more embedded in their organization and in their community. 
WHEN STAYING IS DISSATISFYING

Hypothesis 5': On-the-job embeddedness (5a') and off-the-job embeddedness (5b') strengthen the relationship between stayers' initial turnover cognitions and their subsequent career satisfaction in the sense that this relationship is more negative if people are more embedded in their organization and in their community.

To test our hypotheses, we performed two studies. In study 1, we examined the baseline relationship (i.e., hypothesis 1) and the moderating role of internal job transitions, lack of external job opportunities, and job embeddedness (hypotheses 3-5). In study 2, we retested hypothesis 1 and examined the mediating role of justifiability and regret (hypotheses 2).

\section{STUDY 1}

\section{Procedure}

We conducted a two-wave study with white-collar employees from four organizations in Belgium. Each organization had different branches across the country and offered similar career opportunities to their employees (i.e., promotions, functional changes, and relocations to other domestic branches within the companies). The first round of data collection (T1) resulted in 342 questionnaires (response rate: 54\%) and the second round (T2), one year later, in 226 valuable responses (response rate: $66.1 \%$ ). To ensure that the respondents at T2 included only stayers, we contacted respondents at T2 via their company e-mail address and explicitly confirmed that they were still working at the same company.

We performed a dropout analysis to examine whether or not the dropout at T2 was selective (cf. Goodman \& Blum, 1996). We found no significant differences between the respondents and the non-respondents at $\mathrm{T} 2$ with respect to turnover cognitions, lack of external job opportunities, on-the job embeddedness, off-the-job embeddedness, career satisfaction or any of the controls at T1. Hence, the dropout seems to be non-selective.

The final sample consisted of $47.3 \%$ women. The average age was 41.6 years, with $28.6 \%$ of the respondents being younger than 35 years, $34.1 \%$ between 35 and 45 years old, 
WHEN STAYING IS DISSATISFYING

and $37.3 \%$ older than 45 . Almost half of the respondents $(45.9 \%)$ had a master's degree.

\section{Measures}

Turnover cognitions. Turnover cognitions were measured at $\mathrm{T} 1$ with the three-item scale of Jiang and Klein (2002). A sample item is "I think a lot about leaving this organization." Responses were rated on a five-point Likert scale $(1=$ strongly disagree; $5=$ strongly agree). The scale had a good internal consistency (Cronbach's alpha $=.91)$.

Internal job transitions. We asked respondents at T2 whether they had made an internal promotion, whether they had changed functional domains, and/or whether they had moved to another domestic branch of their company in the past year (1: yes; $0:$ no). These questions were grouped into a new variable, "internal job transition," which is 1 if the person made an internal job transition between $\mathrm{T} 1$ and $\mathrm{T} 2$ and 0 otherwise.

Lack of external job opportunities. The measure for lack of external job opportunities was constructed based on labor market data provided by the Flemish Policy Research Center for Work (www.steunpuntwerk.be). In particular, we calculated the average of the national and regional (provincial) age- and gender-specific unemployment rate for the period between the two measurement moments. We opted for the age- and gender-specific rather than the occupation-specific unemployment rate because people can choose to cross occupational boundaries - especially in today's increasingly boundaryless career era (Arthur \& Rousseau, 2001) — whereas people cannot change their age or gender. As such, age and gender are factors that are more "out of the control" of the individual, and, therefore, this choice fits better with our reasoning that a high unemployment rate may mitigate the impact of initial turnover cognitions because it is an external explanation (i.e., out of people's immediate control) that helps to justify staying and to get psychological closure. In addition, several studies have shown that people are indeed affected by this unemployment rate. For instance, the regional and the gender- and age-specific unemployment rate have been shown to affect 
WHEN STAYING IS DISSATISFYING

people's labor market mobility (Kuhn \& Sweetman, 1998; Rokicka, 2016) as well as their wellbeing (Clark, 2003; Moscone, Tosetti, \& Vittadini, 2016).

On-the-job embeddedness. On-the-job embeddedness was measured at $\mathrm{T} 1$ with $\mathrm{Ng}$ and Feldman's (2009) 15-item version of Mitchell et al.'s (2001) original 26-item on-the-job embeddedness scale. This measure is a formative - or causal indicator-index that is theorized to aggregate to overall on-the-job embeddedness (Mitchell et al., 2001). All 15 items were numeric; yet, the response scale differed across items, with some items being assessed with open-ended questions (e.g., "How many co-workers are highly dependent on you?"), whereas others were assessed using a five-point Likert scale (e.g., "I feel like I am a good match for this company"). Therefore, all items were standardized prior to aggregation. Following Mitchell et al. (2001), the items were first averaged per dimension (fit, links, and sacrifices), and then the dimension scores were averaged into a composite score. In this way, all three dimensions contributed equally to the composite score. We assessed the reliability of this formative construct using the Variance Inflation Factor (VIF) score since the Cronbach's alpha is considered to be inappropriate for formative measures (Diamantopoulos \& Siguaw, 2006). The VIF scores of the different indicators were all below the required threshold of five (Hair, Black, Babin, \& Anderson, 2010; Rogerson, 2001), which supports the reliability of our measure (Diamantopoulos \& Siguaw, 2006).

Off-the-job embeddedness. Off-the-job embeddedness was assessed at T1 with nine items of the original 14-item off-the-job-embeddedness scale of Mitchell et al. (2001). We opted for a shortened scale to reduce the length of our questionnaire and which is in line with our use of a shortened version of on-the-job embeddedness. We included three items for each of the three sub-dimensions. Items were selected based on the factor loadings reported by Mitchell et al. (2001) and on the comparability with the content of the corresponding on-thejob embeddedness dimension (see Appendix A for an overview of the included items). Since 


\section{WHEN STAYING IS DISSATISFYING}

this measure also combined different response scales—-such as five-point Likert scales (e.g., "I really love the place where I live"; 1: strongly disagree to 5: strongly agree) and dummyscores (e.g., “Are you married?”: 1: yes, 0: no)—the items were standardized before aggregation into dimension scores (fit, links, and sacrifices). Following Mitchell et al. (2001), we then averaged the dimension scores into a composite score. The VIF scores of the different indicators were all below the threshold of five (Hair et al., 2010; Rogerson, 2001), which supports the reliability of this formative measure (Diamantopoulos \& Siguaw, 2006).

Career satisfaction. Career satisfaction was measured at T2 using the single item measure of Verbruggen and Sels (2010). Respondents were asked to indicate their overall level of career satisfaction on a Likert-type scale ranging from one (extremely dissatisfied) to seven (extremely satisfied). Nagy (2002) demonstrated that single-item measures of facet satisfaction (e.g., career satisfaction) compare quite favorably with multiple-item measures in producing similar correlations with turnover cognitions.

Control variables. We controlled for gender (1: female; 0 : male), full-time contract (1: yes; 0 : no), the organization (by including a dummy per organization), and career satisfaction at $\mathrm{T} 1$ (assessed with the same single-item measure used at T2, which was described above).

\section{Analyses and Results}

To test the hypotheses, we conducted moderated hierarchical regression analyses using SPSS 24. All non-dichotomous variables were mean-centered to remove non-essential multicollinearity (Cohen, Cohen, West, \& Aiken, 2002). We entered the control variables, including career satisfaction at T1 in the first step, the main effects in the second step, and the interaction term in the final step (Baron \& Kenny, 1986). Since multiple two-way interactions increase the risk of Type I errors (Cohen et al., 2002), we tested our moderation hypotheses by assessing each two-way interaction independently, which is a common practice in the case of multiple interactions (e.g., Lam, Peng, Wong, \& Lau, 2017; Zheng, Singh, \& Chung, 


\section{WHEN STAYING IS DISSATISFYING}

2017). When the interaction terms were found to be significant $(p<.05)$ or to approach significance $(p<.10)$, we plotted the interaction, computed the simple slopes, and-for the continuous moderators - computed the regions of significance (Johnson-Neyman technique; Preacher, Curran, \& Bauer, 2006).

Table 1 presents the descriptive statistics and correlations among this study's variables. The results of the regression analyses are shown in Table 2.

$<$ Insert Table 1 and Table 2 about here $>$

Hypothesis 1 proposed a negative relationship between initial turnover cognitions and subsequent career satisfaction. As can be seen in Table 2, we found a significant negative relationship between initial turnover cognitions and subsequent career satisfaction in all regressions. This supports hypothesis 1 .

Hypothesis 3 proposed a moderating effect of internal job transitions. As shown in Model 1 in Table 2, the interaction term with internal job transitions was trending toward significance $(p=.081)$. Simple slope tests (Hayes, 2012) further revealed that the relationship of turnover cognitions at $\mathrm{T} 1$ and career satisfaction at T2 was significantly negative for people who did not make an internal job transition (simple slope $=-.32 ; p<.01$ ) but not significant for people who had made an internal job transition between $\mathrm{T} 1$ and $\mathrm{T} 2$ (simple slope $=-.04 ; p$ $=.805)$ (for a visualization, see Figure 1, upper panel). These results provide marginal support for hypothesis 3 .

$<$ Insert Figure 1 about here $>$

Hypothesis 4 predicted a mitigating impact of a lack of external job opportunities. In line with this hypothesis, we found a significant positive interaction effect of this variable (see Table 2, Model 2). We plotted this interaction in the middle panel in Figure 1. The figure shows a strong negative relationship between initial turnover cognitions and subsequent career satisfaction when there is no lack of external job opportunities-that is, when the 


\section{WHEN STAYING IS DISSATISFYING}

unemployment rate is low (simple slope at $-1 \mathrm{SD}=-0.52 ; p<.01$ )-whereas no significant impact is found when there is a large lack of external job opportunities-referring to when the unemployment rate is high (simple slope at $+1 \mathrm{SD}=-0.04 ; p=.657$ ). So, the relationship between stayers' initial turnover cognitions and their subsequent career satisfaction is more negative when there are more external job opportunities available. These findings are in line with hypothesis 4 . The region of significance analysis further showed that for mean-centered unemployment rate levels up to 0.73 , turnover cognitions were associated in a significantly negative way $(p<.05)$ with subsequent career satisfaction, whereas for very high meancentered unemployment rate levels of 3.98 and higher, turnover cognitions were significantly positively $(p<.05)$ associated with career satisfaction.

Hypotheses 5a and 5a' concerned the moderating role of on-the-job embeddedness. As can be seen in Table 2 (Model 3), no significant moderation effect was found $(p=.45)$. Hence, we have to reject both hypotheses $5 \mathrm{a}$ and $5 \mathrm{a}$ '.

Finally, hypotheses 5b and 5b' concerned the moderating role of off-the-job embeddedness. As can be seen in Table 2 (Model 4), the interaction effect was found to be significant $(p<.05)$. We plotted this interaction in the lower panel of Figure 1. We see that initial turnover cognitions had a stronger negative impact on career satisfaction when the employee was more off-the-job embedded (simple slope at $+1 \mathrm{SD}=-0.52 ; p<.01$ ) than when off-the-job embeddedness was low (simple slope at $-1 \mathrm{SD}=-0.17 ; p=.078$ ). Thus, off-thejob embeddedness was found to amplify the negative relationship between turnover cognitions and subsequent career satisfaction. The region of significance analysis further showed that for mean-centered off-the-job embeddedness values of -0.58 and higher, the relationship between turnover cognitions and subsequent career satisfaction is significantly negative $(p<.05)$. For mean-centered off-the-job embeddedness values lower than -4.64 , this relationship would be significantly positive $(p<.05)$; however, we had no observations with 
WHEN STAYING IS DISSATISFYING

such low values in our dataset. Overall, these results show support for hypothesis 5b' (which built on regret theory) and not for hypothesis $5 \mathrm{~b}$ (which built on the insufficient justification perspective).

We performed some additional analyses using the PROCESS macro, model 74, of Hayes (2012) with 1,000 bootstrap samples to check whether the moderating effects hold when we simultaneously control for the influence of the moderating variables on turnover cognitions at T1 (e.g., Mitchell et al., 2001). Model 74 tests a specific form of moderated mediation in which certain determinants of a phenomenon are expected to also moderate the relationship between that phenomenon and an outcome (Hayes, 2012). These analyses confirmed the three moderation effects as reported above.

\section{Conclusions}

Study 1 found support for our baseline hypothesis that stayers' initial turnover cognitions are negatively related with their subsequent career satisfaction. In addition, in line with the regret argument and partially with the justifiability argument, we found marginal support for hypothesis 3 (i.e., the mitigating role of internal job transitions), support for hypothesis 4 (i.e., the mitigating role of lack of external job opportunities), and support for hypothesis 5b' (i.e., the amplifying role of off-the-job embeddedness). The latter result suggests that in the case of off-the-job embeddedness, the regret path may be stronger than the justifiability path. No moderating effect was found for on-the-job embeddedness (i.e., hypotheses 5a and 5a'). This could perhaps be because for on-the-job embeddedness, the regret and justifiability paths neutralize each other. However, this study does not allow us to make statements about the mediating mechanisms or their relative importance. In addition, since we did not measure turnover cognitions at $\mathrm{T} 2$, we cannot rule out reversed causality.

\section{STUDY 2}

We performed a second study to examine the mediating role of regret and justifiability, 


\section{WHEN STAYING IS DISSATISFYING}

the two key explanatory mechanisms we used to develop our hypotheses. In that way, we can assess the relative importance of these two paths (i.e., justifiability or regret). In addition, this study addresses two methodological shortcomings of study 1 by (a) testing whether the initial turnover cognitions-subsequent career satisfaction relationship holds when we control for the reverse-causation hypothesis, that is, that initial career satisfaction affects people's subsequent turnover cognitions, and (b) by controlling in the analysis for job satisfaction, organizational commitment, and negative shock events — three typical antecedents of turnover thoughts — in order to exclude the possibility that our results are due to turnover cognitions functioning as a marker for these variables.

\section{Procedure}

A three-wave study was conducted with employees from seven Belgian organizations. The organizations operated in different economic industries (i.e., banking, electronics, consulting, medical technology, education, local government, and not-for-profit) and were all employing more than 250 employees. The first wave resulted in 2,079 usable questionnaires (response rate of $42 \%$ ). The second wave, conducted six months later, resulted in 1,056 responses (response rate of 51\%), and the third wave, again six months later, resulted in 705 responses (response rate of 67\%). As we targeted stayers, we used the company's e-mail address and included the check question "Did you leave your employer in the past six months?"

A dropout analysis (cf. Goodman \& Blum, 1996) revealed that respondents at T2 and T3 did not differ significantly from non-respondents on demographics, career satisfaction, or turnover cognitions (all measured at T1). The dropout thus seems to be non-selective.

The final sample consisted of $39.1 \%$ women. The average age was 41 years, with $31.3 \%$ of the respondents being younger than 35 years, $32.1 \%$ between 35 and 45 , and $36.6 \%$ older than 45. Forty-one percent of the respondents had a master's degree. 
WHEN STAYING IS DISSATISFYING

\section{Measures}

Turnover cognitions. We measured turnover cognitions at $\mathrm{T} 1$ and $\mathrm{T} 3 \mathrm{using}$ three items similar to the ones in study 1 . A sample item is "I think about leaving this organization." Items were rated on a five-point Likert scale ranging from one (strongly disagree) to five (strongly agree). We assessed the reliability of this measure by examining the composite reliability (composite reliability at $\mathrm{T} 1=.93$; composite reliability at $\mathrm{T} 3=.93$ ) and the average variance extracted $(\mathrm{AVE}$ at $\mathrm{T} 1=.81 ; \mathrm{AVE}$ at $\mathrm{T} 3=.82)$. Since all indicators exceeded the required thresholds (i.e., .70 for the composite reliability and .50 for the AVE; Hair et al., 2010), this measure was found to be reliable.

Regret. Regret was measured at T2 with the three-item scale of Inman and Zeelenberg (2002). This scale was adapted to relate to "not having changed jobs in the past six months". A sample item is "I regret that I didn't change jobs in the past six months" (1: strongly disagree; 5: strongly agree). The scale turned out to have a good reliability (composite reliability $=.87 ; \mathrm{AVE}=.69)$.

Justifiability. Justifiability was measured at T2 with the three-item justifiability scale of Inman and Zeelenberg (2002). The scale was adapted to relate to "not having changed jobs in the past six months." A sample item is "I can easily explain why I didn't change jobs in the past six months" (1: strongly disagree; 5: strongly agree). One item, "It is logical that I didn't change jobs in the past six months," had to be deleted due to low factor loading. The remaining two-item scale turned out to be reliable (composite reliability $=.73$; AVE $=.57$ ).

Career satisfaction. Career satisfaction was measured at T1 and T3 with the five-item career satisfaction scale of Greenhaus, Parasuraman, and Wormley (1990). A sample item is "I am satisfied with the progression I have made toward my personal goals." Respondents were asked to rate the items on a five-point Likert scale from one (strongly disagree) to five (strongly agree). The scale was found to be reliable at both $\mathrm{T} 1$ (composite reliability $=.88$; 
WHEN STAYING IS DISSATISFYING

$\mathrm{AVE}=.60)$ and $\mathrm{T} 3($ composite reliability $=.87 ; \mathrm{AVE}=.58)$.

Control variables. We tested a model including gender $(1=$ female; $0=$ male $)$, fulltime contract $(1=$ yes; $0=$ no), job satisfaction (one-item scale of Dolbier, Webster, McCalister, Mallon, \& Steinhardt, 2005), organizational commitment (four-item scale of De Cuyper \& De Witte, 2008), and negative shock events (four-item measurement of Burton et al., 2010). Since the control variables did not affect our conclusions, we decided to report the results of the analysis without any control variable.

\section{Analyses and Results}

We performed confirmatory factor analyses and structural equation modeling using SAS version 9.2. We first investigated the measurement invariance of turnover cognitions and career satisfaction, which were both assessed at two occasions (i.e., T1 and T3). The model with fixed factor loadings over time did not differ significantly from the model in which the loadings were allowed to fluctuate freely over time $\left(\Delta \chi^{2}=5.75, \mathrm{df}=8, p>.10\right)$, suggesting that the factor structure of both constructs remained stable over time.

The full measurement model with six factors (turnover cognitions T1, turnover cognitions $\mathrm{T} 3$, regret $\mathrm{T} 2$, justifiability $\mathrm{T} 2$, career satisfaction $\mathrm{T} 1$, and career satisfaction $\mathrm{T} 3$ ) turned out to have a good overall fit (see Table 3), and all items loaded significantly on the intended factors $(p<.01)$. The six-factor model turned out to have a significantly better fit than the five-factor model (turnover cognitions T1, turnover cognitions T3, regret + justifiability $\mathrm{T} 2$, career satisfaction $\mathrm{T} 1$, and career satisfaction $\mathrm{T} 3$ ), the three-factor model (T1 variables, T2 variables, and T3 variables), and the single-factor model (see Table 3).

$<$ Insert Table 3 about here $>$

Table 4 shows the descriptives and correlations among the key variables.

$<$ Insert Table 4 about here $>$

Before testing the mediating role of justifiability and regret (hypothesis 2), we first 


\section{WHEN STAYING IS DISSATISFYING}

examined whether the relationship between turnover cognitions and subsequent career satisfaction holds when we control for the reverse-causation hypothesis, being that initial career satisfaction affects people's subsequent turnover cognitions. We therefore tested a cross-lagged panel model between turnover cognitions and career satisfaction (Zapf, Dormann, \& Frese, 1996). Figure 2 shows the results of this structural equation analysis $\left(\mathrm{X}^{2}(96)=244.00 ; p<.01 ; \mathrm{SRMR}=.03 ; \mathrm{RMSEA}=.05\right.$ with $\left.90 \% \mathrm{CI}=[.04 ; .05] ; \mathrm{CFI}=.98\right)$ As can be seen from Figure 2, the negative relationship between initial turnover cognitions at $\mathrm{T} 1$ and subsequent career satisfaction at $\mathrm{T} 3$ remains significant $(\mathrm{B}=-0.11 ; p<.01)$ when the reverse causal relationship is modeled. This reconfirms our first hypothesis that stayers' initial turnover cognitions are negatively related with their subsequent career satisfaction.

$<$ Insert Figure 2 about here $>$

To test hypothesis 2, we tested a structural mediation model (see Figure 3). This model turned out to have a good overall fit $\left(\mathrm{X}^{2}(174)=433.74 ; p<.01 ; \mathrm{SRMR}=.07 ; \mathrm{RMSEA}=.05\right.$ with $90 \% \mathrm{CI}=[.04 ; .05] ; \mathrm{CFI}=.98)$. Note that we also modeled the autocorrelations between turnover cognitions at $\mathrm{T} 1$ and $\mathrm{T} 3$ and between career satisfaction at $\mathrm{T} 1$ and $\mathrm{T} 3$ as well as the reverse causal relationship between career satisfaction at $\mathrm{T} 1$ and turnover cognitions at $\mathrm{T} 3$, but to ease the interpretation we did not include these variables in Figure 3.

$<$ Insert Figure 3 about here $>$

As can be seen in Figure 3, turnover cognitions at $\mathrm{T} 1$ are negatively related with justifiability at T2 $(\mathrm{B}=-0.24 ; p<.01)$ and positively with regret at $\mathrm{T} 2(\mathrm{~B}=0.53 ; p<.01)$. Justifiability at T2 is in turn positively related with career satisfaction at $\mathrm{T} 3(\mathrm{~B}=-0.10 ; p<$ $.05)$, whereas regret at $\mathrm{T} 2$ is negatively related with career satisfaction at $\mathrm{T} 3(\mathrm{~B}=-0.15 ; p<$ .01). A Sobel test confirmed the significant negative indirect effect of turnover cognitions on subsequent career satisfaction via both regret $(\mathrm{B}=-0.08 ; p<.01)$ and justifiability $(\mathrm{B}=-0.02$; $p<.05)$. This confirms hypothesis 2 . These findings suggest that people who have stronger 


\section{WHEN STAYING IS DISSATISFYING}

initial turnover cognitions experience lower subsequent career satisfaction because they find it hard to justify that they stayed in their organization and because they regret not having left.

Note also that the regret path is four times as strong as the justifiability path, which can explain why we found more support for the regret path than for the justifiability path in study 1 (cf. the amplifying rather than the mitigating role of off-the-job embeddedness).

\section{GENERAL DISCUSSION}

Although the topic of turnover cognitions has attracted widespread research attention in the past 50 years (Hom et al., 2017), scholars have only recently started to examine outcomes of turnover cognitions for employees who ended up staying in their organization (Mai et al., 2016). Even less is known about the internal processes induced by turnover thoughts that can explain outcomes among stayers in the longer run (Rothausen et al., 2017). Insight into this matter is, however, crucial to intervene in the process and to address any deleterious outcomes that unrealized turnover desires may induce over time. The aim of this study was therefore to improve our understanding of these processes. Building on the insufficient justification perspective and regret theory, we argued that the stronger the stayers' initial turnover cognitions, the harder they would find it to justify their staying in the organization and the more they were likely to have regret about not having left the organization, two internal processes which are likely to lower their subsequent career satisfaction. In addition, we expected the turnover cognitions-subsequent career satisfaction relationship to be moderated by contextual factors that can explain why people stayed with their organization. The results of our two studies were largely consistent with our arguments. The hypothesis that initial turnover cognitions are negatively related with subsequent career satisfaction was confirmed in both studies. Study 1 additionally found support for several contextual factors moderating the negative relationship between turnover cognitions and subsequent career satisfaction. In particular, we found marginal support for the mitigating role of internal job transitions, 


\section{WHEN STAYING IS DISSATISFYING}

support for the mitigating role of lack of external job opportunities, no support for the moderating role of on-the-job embeddedness, and support for the amplifying role of off-thejob embeddedness. The latter result suggests that the regret path may be stronger than the justifiability path. Study 2 confirmed the mediating role of both justifiability and regret and suggested that although both processes are additive, the regret path was stronger than the justifiability path.

Our findings add to the literature in several ways. First, our results showed that insufficient justifiability and regret are important internal processes through which turnover cognitions can induce outcomes among stayers in the longer run. More specifically, we found that stayers who had initial turnover thoughts had lower subsequent career satisfaction because they had more difficulties in justifying their current career situation (i.e., their staying in the organization) and because they experienced more regret about not having left. It is interesting that the regret path—which has received, to the best of our knowledge, no attention in studies on outcomes of turnover cognitions among stayers - was found to be stronger than the justifiability path, which has been mentioned sporadically (e.g., Burton et al., 2010). So, career dissatisfaction among stayers with initial turnover cognitions seems to be induced more by counterfactual thoughts that keep confronting them with "what could have been" than by difficulties with justifying their turnover cognitions-turnover inconsistency. Future research may further explore these processes and other potential outcomes they may induce, such as reduced health (Lee, Jung, Jang, Kim, Chung, \& Chae, 2017) and lowered psychological wellbeing (Jokisaari, 2003). Research on this topic could further broaden our knowledge on outcomes of turnover cognitions among stayers, which seems a highly relevant research avenue as most employees who have turnover thoughts at a certain point end up staying with their employer.

Note that insufficient justifiability and regret may be primarily relevant to understand 


\section{WHEN STAYING IS DISSATISFYING}

outcomes of staying in the longer run because both processes require some time to manifest. Indeed, in the short run, people with initial turnover cognitions do not yet need to justify their staying since the process of leaving requires time anyway. Similarly, regret implies prefactual thoughts to evolve into counterfactual thoughts, which also requires time to pass. The fact that both processes require time to manifest may explain why they have received so little attention in the extant research on outcomes of turnover cognitions, which has mainly used short timeframes of a couple of weeks (e.g., Burris et al., 2008; Burton et al., 2010; Mai et al., 2016). An interesting question in this respect is how much time needs to pass for these processes to occur. In this study, we used a timeframe of one year, which is a timespan that is often used in research on the link between turnover cognitions and actual turnover and thus seems a reasonable amount of time to realize one's turnover thoughts. Yet, future research may want to experiment with different timeframes to explore when these internal processesand the outcomes they bring along — start manifesting themselves.

Second, this study expands our understanding of the relationship between turnover cognitions and career satisfaction. Most of the previous studies that have examined this relationship were cross-sectional and modeled the impact of career satisfaction on turnover cognitions (e.g., Nauta et al., 2009). This study looked at this relationship longitudinally and found support for both the normal and the reverse relationship. That is, while lower career satisfaction was related with higher subsequent turnover cognitions, we also found that for employees who stayed with their employer, initial turnover cognitions resulted in lower subsequent career satisfaction. It thus seems that if turnover cognitions remain unrealized, they set in motion a process that amplifies people's career dissatisfaction. This points to a complex and dynamic interplay between career satisfaction and turnover cognitions.

Third, our findings add to the understanding of how career satisfaction evolves over time. The few longitudinal studies on career satisfaction have typically focused on the impact 


\section{WHEN STAYING IS DISSATISFYING}

of an observable career step, such as taking a career break, getting a raise, or participation in career counseling (Schneer \& Reitman, 1997; Spurk \& Abele, 2014; Verbruggen \& Sels, 2008). We found evidence that "what did not happen" can also affect people's career satisfaction, depending on the consistency between their preceding cognitions and their current career situation. This is in line with psychology research, which has long shown that people's satisfaction with a certain life domain is not influenced so much by their objective accomplishments as such but more by how their actual situation compares with some reference point, like their preceding cognitions (Kahneman, 1999). Future research on career satisfaction should therefore go beyond studying what happens and also take into account inactions and non-occurrences as well as people's preceding career cognitions.

Fourth, this study showed how contextual factors affect the turnover cognitionssubsequent career satisfaction relationship. For internal job transitions, we found marginal support for a mitigating effect on the turnover cognitions-career satisfaction relationship. In particular, the negative relationship between turnover cognitions and stayers' subsequent career satisfaction disappeared when stayers had made an internal job transition. This finding confirms earlier research that career satisfaction is affected by short-term changes even within one organization (e.g., Schneer \& Reitman, 1997). In addition, it suggests that stayers see internal job transitions as a worthy alternative to organizational turnover. Future research may further examine this relationship and study, for instance, whether this relationship holds true for all individuals. Indeed, some individuals may inherently prefer one transition over the other. For instance, risk-averse individuals may have a preference for an internal job transition since staying entails fewer risks (Allen et al., 2005), whereas individuals with an organizational mobility preference (Briscoe, Hall, \& DeMuth, 2006) are more likely to prefer switching organizations. Relatedly, it remains unclear whether internal job transitions help to permanently resolve the issues underlying people's turnover cognitions or whether people's 


\section{WHEN STAYING IS DISSATISFYING}

turnover cognitions linger and perhaps resurface whenever they encounter a setback in their new position. Future longitudinal research may look into these issues to better understand when and for whom turnover and internal job transitions are worthy alternatives.

A lack of external job opportunities was also found to mitigate the turnover cognitionssubsequent career satisfaction relationship. This is an interesting finding since it challenges the dominant assumption that turnover cognitions are especially harmful when limited job opportunities prevent people who want to leave from actually doing so (Bowen, 1982; Hom et al., 2012; Mai et al., 2016). The results of this study suggest that turnover cognitions are less impactful when external job opportunities are limited, probably because a turnover cognitions-turnover inconsistency is then easier to justify and induces less self-blame and regret. What is more, the region of significance analysis showed that in the case of a very high unemployment rate, stayers with initial turnover cognitions tend to be more satisfied with their career, possibly because they are relieved to not have acted on their turnover cognitions as this would likely have resulted in unemployment.

Finally, we found no moderating effect of on-the-job embeddedness, whereas off-thejob embeddedness was found to amplify the negative relationship between turnover cognitions and stayers' subsequent career satisfaction. Perhaps, the justifiability path is stronger in the case of on-the-job embeddedness than in the case of off-the-job embeddedness, for instance, because same-context explanations feel more convincing, and therefore the regret path may be nullified in the former case, whereas it predominates in the latter case. This difference between on-the-job and off-the-job embeddedness points to a potential risk of using global embeddedness measures. Global measures see embeddedness as global construct consisting of the whole of on-the-job and off-the-job forces that keep an employee within an organization (Crossley, Bennett, Jex, \& Burnfield, 2007). By not distinguishing between onand off-the-job forces, however, researchers using a global measure risk missing important 


\section{WHEN STAYING IS DISSATISFYING}

differences between both types of embeddedness.

The finding that off-the-job embeddedness amplifies the turnover cognitions-career satisfaction relationship further points to a potential downside of embeddedness. Job embeddedness is generally seen in a positive light and has been linked to several individual and organizational benefits (e.g., Ng \& Feldman, 2009). Only recently, potential risks of embeddedness have begun to be examined (Allen, Peltokorpi, \& Rubenstein, 2016; Ng \& Feldman, 2012). Allen and colleagues (2012), for instance, found that the effects of being in an adverse work environment (e.g., having an abusive supervisor) were worse for employees who were more embedded in their job, and $\mathrm{Ng}$ and Feldman (2012) found that both on-the-job and off-the-job embeddedness related to an increase in work-life conflict over time. This study adds to this line of research by showing that when off-the-job embeddedness keeps people from following through on their turnover cognitions, this may come at the cost of significantly lowered career satisfaction. It seems interesting for future research to further look into this "dark side" of job embeddedness.

\section{Practical Implications}

This study's findings indicate that keeping employees who have had turnover thoughts is not without risks for organizations since these thoughts - when they remain unrealizedmay set in motion internal processes which induce negative outcomes among these stayers in the longer run. It is therefore in the interest of organizations to help employees with preceding turnover thoughts to deal with these internal processes. Coaching may be relevant in this respect since a coach can help stayers with preceding turnover cognitions to make sense of and justify their turnover cognitions-turnover inconsistency (Connolly \& Zeelenberg, 2002) and/or teach regret regulation strategies (Pieters \& Zeelenberg, 2007), such as re-appraising the turnover option by generating semifactual (or "even if") thoughts rather than counterfactual thoughts (e.g., "Even if I had left my employer, I would probably still have no 


\section{WHEN STAYING IS DISSATISFYING}

work-life balance since I am a workaholic"; McCloy \& Byrne, 2002). Since this type of coaching will only work when employees trust their coach (Gelso \& Carter, 1985), it is important to create a safe context, for instance, by offering coaching opportunities with a "neutral" coach (e.g., not the direct supervisor) and by guaranteeing the confidentiality of the coaching sessions (OECD, 2004).

In addition, it seems important for organizations to use retention strategies that not only retain employees but that can also counteract the negative effect of unrealized turnover cognitions. A possible way to do this is — as we saw in this study—by offering internal job opportunities. However, other strategies, such as changing the work content or adapting employees' working hours, could be effective as well. Future research may be needed to examine these strategies' potential to address the negative consequences of reluctant staying. In addition, organizations may want to take proactive measures to prevent employees from thinking about leaving. Offering career opportunities, good overall HR management, and qualitative leadership are some practices suggested in the literature to this end.

\section{Limitations and Suggestions for Future Research}

By using a two-study design, we were able to show the consistency of the baseline hypothesis in two settings. In addition, the panel data allowed us to reduce the risk of common method variance and to provide a stronger case for the proposed directionality (Podsakoff, MacKenzie, Lee, \& Podsakoff, 2003). Yet, several limitations should be mentioned as well. First, we were unable to test all our hypotheses in one mediated moderation model. Accordingly, we could not determine whether the moderation effects we found were indeed due to an effect on justifiability and regret. Future research may want to address this limitation by testing the full mediated moderation model using one dataset. Second, we tested our hypotheses with specific samples of Flemish employees. Future research should test the generalizability of our findings to other groups of employees as well 


\section{WHEN STAYING IS DISSATISFYING}

as in other cultural and geographical settings. Third, we used a single-item scale to measure career satisfaction in our first study, with single-item measures being sometimes questioned regarding their validity and reliability. Though we found support for the baseline hypothesis when we used a multiple-item career satisfaction scale, it could be valuable for future research to also replicate our moderating hypotheses using a multiple-item career satisfaction scale. Fourth, we did not differentiate between different forms of internal job transitions nor did we assess whether or not the internal job transitions were voluntary. Accordingly, we cannot rule out that different types of internal job transition may have different effects. Fifth, we measured lack of external job opportunities by the actual unemployment rate. Because this is an objective measure, it reduces the risk of common method variance. In addition, research has shown that it is the actual rather than the perceived job availability that predicts whether people realize their turnover cognitions (Gerhart, 1990). Nevertheless, future research may want to examine whether similar results are found for the perceived availability of jobs. Sixth, in line with most research on job embeddedness (Lee et al., 2014), we did not differentiate between the three sub-dimensions of job embeddedness: fit, links, and sacrifices. However, as Hom and colleagues (2012) argue, staying because of fit versus staying to not lose benefits may have different effects. Future research may explore whether the different sub-dimensions of job embeddedness have similar or rather dissimilar effects.

\section{Conclusion}

In sum, this study showed that initial turnover cognitions can affect outcomes among stayers in the longer run because employees with stronger initial turnover cognitions have more difficulties justifying why they stayed, and they experience more regret about not having left. Overall, these findings call for more theoretical and empirical work on staying despite initial turnover cognitions to improve our understanding of the complexity and dynamic nature of the turnover/retention phenomenon (cf. Rothausen et al., 2017). 
WHEN STAYING IS DISSATISFYING

\section{REFERENCES}

Abele, A. E., \& Spurk, D. 2009. How do objective and subjective career success interrelate over time? Journal of Occupational and Organizational Psychology, 82: 803-824.

Allen, D. G., Peltokorpi, V., \& Rubenstein, A. L. 2016. When “embedded” means "stuck": Moderating effects of job embeddedness in adverse work environments. Journal of Applied Psychology, 101: 1670- 1686.

Allen, D., Weeks, K., \& Moffitt, K. 2005. Turnover cognitions and voluntary turnover: The moderating roles of self-monitoring, locus of control, proactive personality, and risk aversion. Journal of Applied Psychology, 90: 980-990.

Arthur, M. B., \& Rousseau, D. M. 2001. The boundaryless career: A new employment principle for a new organizational era. Oxford University Press on Demand.

Baron, R. M., \& Kenny, D. A. 1986. The moderator-mediator variable distinction in social psychological research: Conceptual, strategic and statistical considerations. Journal of Personality and Social Psychology, 51: 1173-1182.

Beike, D. R., Markman, K. D., \& Karadogan, F. 2009. What we regret most are lost opportunities: A theory of regret intensity. Personality and Social Psychology Bulletin, 35: 385-397.

Bettman, J. R., Luce, M. F., \& Payne, J. W. 1998. Constructive Consumer Choice Processes. Journal of Consumer Research, 25: 187-217.

Bowen, D. 1982. Some unintended consequences of intention to quit. Academy of Management Review, 7: 205-211.

Briscoe, J. P., Hall, D. T., \& DeMuth, R. L. F. 2006. Protean and boundaryless careers: An empirical exploration. Journal of Vocational Behavior, 69: 30-47.

Bullens, L., van Harreveld, F., \& Forster, J.A. 2011. Keeping ones options open: The detrimental consequences of decision reversibility. Journal of Experimental Social 
WHEN STAYING IS DISSATISFYING

Psychology, 47: 800-805.

Burris, E. R., Detert, J. R., \& Chiaburu, D. S. 2008. Quitting before leaving: the mediating effects of psychological attachment and detachment on voice. Journal of Applied Psychology, 93: 912-922.

Burton, J. P., Holtom, B. C., Sablynski, C. J., Mitchell, T. R., \& Lee, T. W. 2010. The buffering effects of job embeddedness on negative shocks. Journal of Vocational Behavior, 76: 42-51.

Carmon, Z., Wertenbroch, K., \& Zeelenberg, M. 2003. Option attachment: When deliberating makes choosing feel like losing. Journal of Consumer Research, 30: 15-29.

Carson, P., Carson, K., Griffeth, R., \& Steel, R. 1994. Promotion and employee turnover: critique, meta-analysis, and implications. Journal of Business \& Psychology, 8: 455466.

Carson, K. D., Carson, P., Phillips, J. S., \& Roe, C. 1996. A career entrenchment model: theoretical development and empirical outcomes. Journal of Career Development, 22: 273-286.

Chen, G., Ployhart, R. E., Thomas, H., Anderson, N., \& Bliese, P. 2011. The power of momentum: A new model of dynamic relationships between job satisfaction change and turnover cognitions. Academy of Management Journal, 54: 159-181.

Chua, H. F., Gonzalez, R., Taylor, S. F., Welsh, R. C., \& Liberzon, I. 2009. Decision-related loss: regret and disappointment. Neuroimage, 47: 2031-2040.

Clark, A. E. 2003. Unemployment as a social norm: Psychological evidence from panel data. Journal of labor economics, 21: 323-351.

Cohen, J., Cohen, P., West, L., \& Aiken, S. 2002. Applied multiple regression/ correlation analysis for the behavioral sciences. Mahwah, NJ: Erlbaum.

Colakoglu, S. N. 2011. The impact of career boundarylessness on subjective career success: 


\section{WHEN STAYING IS DISSATISFYING}

The role of career competencies, career autonomy, and career insecurity. Journal of Vocational Behavior, 79: 47-59.

Connolly, T., \& Zeelenberg, M. 2002. Regret and decision making. Current Directions in Psychological Science, 11: 212-216.

Cornelißen, T., Hübler, O., \& Schneck, S. 2007. Cyclical effects on job-to-job mobility: An aggregated analysis on microeconomic data. Discussion paper no 371. School of Economics and Management of the Hanover Leibniz University.

Crossley, C., Bennett, R., Jex, S., \& Burnfield, J. 2007. Development of a global measure of job embeddedness and integration into a traditional model of voluntary turnover. Journal of Applied Psychology, 92: 1031-1042.

Dalton, D., \& Todor, W. 1987. The attenuating effects of internal mobility on employee turnover, multiple field assessments. Journal of Management, 13: 705-711.

De Cuyper, N., \& De Witte, H. 2008. Volition and reasons for accepting temporary employment: Associations with attitudes, well-being, and behavioural intentions. European Journal of Work and Organizational Psychology, 17: 363-387.

Diamantopoulos, A., \& Siguaw, J. A. 2006. Formative versus reflective indicators in organizational measure development: A comparison and empirical illustration. British Journal of Management, 17: 263-282.

Dolbier, C. L., Webster, J. A., McCalister, K. T., Mallon, M. W., \& Steinhardt, M. A. 2005. Reliability and validity of a single-item measure of job satisfaction. American Journal of Health Promotion, 19: 194-198.

Donnelly, D. P., \& Quirin, J. J. 2006. An extension of Lee and Mitchell's unfolding model of voluntary turnover. Journal of Organizational Behavior, 27: 59-77.

Dries, N., Pepermans, R., \& Carlier, O. 2008. Career success: Constructing a multidimensional model. Journal of Vocational Behavior, 73: 254-267. 
WHEN STAYING IS DISSATISFYING

Festinger, L. 1957. A Theory of Cognitive Dissonance. Stanford, CA: Stanford University Press.

Gaertner, K. N. 1989. Winning and losing: Understanding managers' reactions to strategic change. Human Relations, 42: 527-546.

Gardner, T. M., Van Iddekinge, C. H., \& Hom, P. W. 2016. If you've got leavin'on your mind: The identification and validation of pre-quitting behaviors. Journal of Management, 0149206316665462.

Gelso, C. J., \& Carter, J. A. 1985. The relationship in counseling and psychotherapy: Components, consequences, and theoretical antecedents. The Counseling Psychologist, 13: $155-243$.

Gerhart, B. 1990. Voluntary turnover and alternative job opportunities. Journal of Applied Psychology, 75: 467-476.

Goodman, J. S., \& Blum, T. C. 1996. Assessing the non-random sampling effects of subject attrition in longitudinal research. Journal of Management, 22: 627-652.

Greenhalgh, L. 1980. A process model of organizational turnover: The relationship with job security as a case in point. Academy of Management Review, 5: 299-303

Greenhaus, J. H., Parasuraman, S., \& Wormley, W. M. 1990. Effects of race on organizational experiences, job performance evaluations, and career outcomes. Academy of Management Journal, 33: 64-86.

Griffeth, R. W., Hom, P. W., \& Gaertner, S. 2000. A meta-analysis of antecedents and correlates of employee turnover, Update, moderator tests, and research implications for the next millennium. Journal of Management, 26: 463-488.

Hafner, R. J., White, M. P., \& Handley, S. 2012. Spoilt for choice: The role of counterfactual thinking in the excess choice and reversibility paradoxes. Journal of Experimental Social Psychology, 48: 28-36. 
WHEN STAYING IS DISSATISFYING

Hair, J. F., Black, W. C., Babin, B. J., \& Anderson, R. E. 2010. Multivariate data analysis (7 ed.). Upper Saddle River, NJ, USA: Prentice-Hall, Inc.

Hausknecht, J. P., Rodda, J., \& Howard, M. J. 2009. Targeted employee retention: Performance-based and job-related differences in reported reasons for staying. Human Resource Management, 48: 269-288.

Hayes, A. F. 2012. PROCESS: A versatile computational tool for observed variable mediation, moderation, and conditional process modeling. Retrieved from: http://www.afhayes.com/public/process2012.pdf.

Heitmann, M., Lehmann, D., \& Herrmann, A. 2007.Choice goal attainment and decision and consumption satisfaction. Journal of Marketing Research, XLIV: 234-250.

Heslin, P. 2005. Conceptualizing and evaluating career success. Journal of Organizational Behavior, 26: 113-136.

Holtom, B. C., Burton, J. P., \& Crossley, C. D. 2012. How negative affectivity moderates the relationship between shocks, embeddedness and worker behaviors. Journal of Vocational Behavior, 80: 434-443.

Hom, P. 2011. Organizational exit. In S. Zedeck (Ed.), Handbook of industrial/organizational psychology (Vol. 2): 67-117. Washington, DC: American Psychological Association.

Hom, P. W., Lee, T. W., Shaw, J. D., \& Hausknecht, J. P. 2017. One hundred years of employee turnover theory and research. Journal of Applied Psychology, 102: 530-545.

Hom, P., Mitchell, T., Lee, T., \& Griffeth, R. 2012. Reviewing employee turnover: focusing on proximal states and an expanded criterion. Psychological Bulletin, 138: 831-858.

Hulin, C. L., Roznowski, M., \& Hachiya, D. (1985). Alternative opportunities and withdrawal decisions: Empirical and theoretical discrepancies and an integration. Psychological Bulletin, 97: 233-250.

Igbaria, M., \& Greenhaus, J. 1992. Determinants of MIS employees' turnover intentions: A 
WHEN STAYING IS DISSATISFYING

structural equation model. Communications of the ACM, 35: 35-49.

Inman, J., \& Zeelenberg, M. 2002. Regret in repeat purchase versus switching decisions: The attenuating role of decision justifiability. Journal of Consumer Research, 29: 116-128.

Jiang, J. J., \& Klein, G. A. 2002. A discrepancy model of information system personnel turnover. Journal of Management Information Systems, 19: 249-262.

Jiang, K., Liu, D., McKay, P. F., Lee, T. W., \& Mitchell, T. R. 2012. When and how is job embeddedness predictive of turnover? a meta-analytic investigation. Journal of Applied Psychology, 97: 1077-1096.

Jokisaari, M. 2003. Regret appraisals, age, and subjective well-being. Journal of Research in Personality, 37: 487-503.

Kahneman, D. 1999. Objective happiness. In D. Kahneman, E. Diener, \& N. Schwarz (Eds.), Well-being: the foundations of hedonic psychology (pp. 3-25). New York: RussellSage.

Kuhn, P., \& Sweetman, A. 1998. Unemployment insurance and quits in Canada. Canadian Journal of Economics, 31: 549-572.

Lam, L., Peng, K., Wong, C., Lau, D. 2017. Is more feedback seeking always better? Leadermember exchange moderates the relationship between feedback-seeking behavior and performance. Journal of Management, 43: 2195-2217.

Lee, T., Burch, T., \& Mitchell, T. 2014. The story of why we stay: A review of job embeddedness. Annual Review of Organizational Psychology and Organizational Behavior, 1: 199-216.

Lee, Y. S., Jung, W. M., Jang, H., Kim, S., Chung, S. Y., \& Chae, Y. 2017. The dynamic relationship between emotional and physical states: An observational study of personal health records. Neuropsychiatric Disease and Treatment, 13: 411-419.

Luce, M. F., Bettman, J. R., \& Payne, J. W. 2001. Emotional decisions: Tradeoff difficulty 


\section{WHEN STAYING IS DISSATISFYING}

and coping in consumer choice. Monographs of the Journal of Consumer Research, 1: $1-209$.

March, J.G., \& Simon, H.A. 1958. Organizations. Oxford, England: Wiley.

Maertz, C. P., \& Kmitta, K. R. 2012. Integrating turnover reasons and shocks with turnover decision processes. Journal of Vocational Behavior, 81: 26-38.

Mai, K. M., Ellis, A. P., Christian, J. S., \& Porter, C. O. 2016. Examining the effects of turnover intentions on organizational citizenship behaviors and deviance behaviors: A psychological contract approach. Journal of Applied Psychology, 101: 1067-1081.

McCloy, R., \& Byrne, R. M. 2000. Counterfactual thinking about controllable events. Memory \& Cognition, 28: 1071-1078.

McCloy, R., \& Byrne, R. M. 2002. Semifactual “even if” thinking. Thinking \& Reasoning, 8: 41-67.

Medvec, V. H., Madey, S. F., \& Gilovich, T. 1995. When less is more: counterfactual thinking and satisfaction among Olympic medalists. Journal of Personality and Social Psychology, 69: 603-610.

Mitchell, T. R., Holtom, B. C., Lee, T. W., Sablynski, C. J., \& Erez, M. 2001. Why people stay: Using job embeddedness to predict voluntary turnover. Academy of Management Journal, 44: 1102-1121.

Mobley, W. H. 1977. Intermediate linkages in the relationship between job satisfaction and employee turnover. Journal of Applied Psychology, 62, 237-240.

Moscone, F., Tosetti, E., \& Vittadini, G. 2016. The impact of precarious employment on mental health: the case of Italy. Social Science \& Medicine, 158: 86-95.

Mowday, R. T., Porter, L. W., \& Steers, R. M. 1982. Employee-organizational linkages: The psychology of commitment, absenteeism, and turnover. New York, NY: Academic Press. 
WHEN STAYING IS DISSATISFYING

Nagy, M. S. 2002. Using a single-item approach to measure facet job satisfaction. Journal of Occupational and Organizational Psychology, 75: 77-86.

Naquin, C. 2003. The agony of opportunity in negotiation: Number of negotiable issues, counterfactual thinking, and feelings of satisfaction. Organizational Behavior and Human Decision Processes, 91: 97-118.

Nauta, A., Van Vianen, A. E. M., Van der Heijden, B. I. J. M., Van Dam, K., \& Willemsen, M. 2009. Understanding the factors that promote employability orientation: the impact of employability culture, career satisfaction and role breadth self-efficacy. Journal of Occupational and Organizational Psychology, 82: 233-251.

Ng, T. W., Sorensen, K. L., Eby, L. T., \& Feldman, D. C. 2007. Determinants of job mobility: A theoretical integration and extension. Journal of Occupational and Organizational Psychology, 80: 363-386.

Ng, T. W. H., \& Feldman, D. C. 2009. Occupational embeddedness and job performance. Journal of Organizational Behavior, 30: 863-891.

Ng, T. W. H., \& Feldman, D. C. 2012. The effects of organizational and community embeddedness on work-to-family and family-to-work conflict. Journal of Applied Psychology, 97: 1233-1251.

Niederman, F., Sumner, M., Maertz, J. R., \& Carl, P. 2007. Testing and extending the unfolding model of voluntary turnover to IT professionals. Human Resource Management, 46: 331-347.

OECD. 2004. Career counseling and public policy. Bridging the gap. Paris: OECD.

Pfeffer, J., \& Lawler, J. 1980. Effects of job alternatives, extrinsic rewards, and behavioral commitment on attitude toward the organization: A field test of the insufficient justification paradigm. Administrative Science Quarterly, 25: 38-56.

Pieters, R., \& Zeelenberg, M. 2005. On bad decisions and deciding badly: When intention- 
WHEN STAYING IS DISSATISFYING

behavior inconsistency is regrettable. Organizational Behavior \& Human Decision Processes, 97: 18-30.

Podsakoff, P., MacKenzie, S., Lee, J., \& Podsakoff, N. 2003. Common method biases in behavioral research: A critical review of the literature and recommended remedies. Journal of Applied Psychology, 88: 879-903.

Podsakoff, N., LePine, J., \& LePine, M. 2007. Differential challenge stressor-hindrance stressor relationships with job attitudes, turnover cognitions, turnover and withdrawal behavior, a meta-analysis. Journal of Applied Psychology, 92: 438-454.

Preacher, K. J., Curran, P. J., \& Bauer, D. J. 2006. Computational tools for probing interactions in multiple linear regression, multilevel modeling, and latent curve analysis. Journal of Educational and Behavioral Statistics, 31: 437-448.

Rokicka, M. 2016. Transition out of self-employment-evidence from Poland. International Journal of Social Economics, 43: 1254-1270.

Roese, N. J. 1997. Counterfactual thinking. Psychological Bulletin, 121, 133-148.

Rogerson, P.A. 2001. Statistical Methods for Geography. London: Sage.

Rothausen, T. J., Henderson, K. E., Arnold, J. K., \& Malshe, A. 2017. Should I stay or should I go? Identity and well-being in sensemaking about retention and turnover. Journal of Management, 43: 2357-2385.

Salancik, G. R., \& Pfeffer, J. 1978. A social information processing approach to job attitudes and task design. Administrative Science Quarterly, 23: 224-253.

Savickas, M. L. 2005. The theory and practice of career construction. In S. Brown \& R. Lent (Eds.), Career development and counseling: Putting theory and research to work: $42-$ 70. Hoboken NJ: John Wiley and Sons.

Schneer, J. A., \& Reitman, F. 1997. The interrupted managerial career path: a longitudinal study of MBAs. Journal of Vocational Behavior, 51: 411-434. 
WHEN STAYING IS DISSATISFYING

Shafir, E., Simonson, I., \& Tversky, A. 1993. Reason-based choice. Cognition, 49: 11-36.

Spurk, D., \& Abele, A. E. 2014. Synchronous and time-lagged effects between occupational self-efficacy and objective and subjective career success: Findings from a four-wave and 9-year longitudinal study. Journal of Vocational Behavior, 84: 119-132.

Steel, R., \& Landon, T. 2010. Internal employment opportunity and external employment opportunity, independent or interactive retention effects? Military Psychology, 22: 282300.

Swider, B. W., Boswell, W. R., \& Zimmerman, R. D. 2011. Examining the job searchturnover relationship: The role of embeddedness, job satisfaction, and available alternatives. Journal of Applied Psychology, 96: 432-441.

Tetlock, P. E. 1985. Accountability: A social check on the fundamental attribution error. Social Psychology Quarterly, 48: 227-236.

van Vianen, A. E., Pater, I. E., \& Preenen, P. T. 2009. Adaptable careers: Maximizing less and exploring more. Career Development Quarterly, 57: 298-309.

Vardaman, J., Allen, D., Renn, R., \& Moffitt, K. 2008. Should I stay or should I go? The role of risk in employee turnover decisions. Human Relations, 61: 1531-1563.

Verbruggen, M. 2012. Psychological mobility and career success in the 'new'career climate. Journal of Vocational Behavior, 81: 289-297.

Verbruggen, M., Sels, L. \& Forrier, A. 2007. Unraveling the relationship between organizational career management and the need for external career counseling. Journal of Vocational Behavior, 71: 69-83.

Verbruggen, M., \& Sels, L. 2010. Social-cognitive factors affecting clients' career and life satisfaction after counseling. Journal of Career Assessment, 18: 3-15.

Westaby, J. D. 2005. Behavioral reasoning theory: Identifying new linkages underlying intentions and behavior. Organizational Behavior and Human Decision Processes, 98: 
WHEN STAYING IS DISSATISFYING

97-120.

Wolff, H. G., \& Moser, K. 2009. Effects of networking on career success: a longitudinal study. Journal of Applied Psychology, 94: 196-206.

Woo, S. E., \& Allen, D. G. 2014. Toward an inductive theory of stayers and seekers in the organization. Journal of Business and Psychology, 29: 683-703.

Zapf, D., Dormann, C., \& Frese, M. 1996. Longitudinal studies in organizational stress research: A review of the literature with reference to methodological issues. Journal of Occupational Health Psychology, 1: 145-169.

Zeelenberg, M., \& Pieters, R. 2007. A theory of regret regulation 1.0. Journal of Consumer psychology, 17: 3-18.

Zeelenberg, M., Van Dijk, W. W., \& Manstead, A. S. 1998. Reconsidering the relation between regret and responsibility. Organizational behavior and human decision processes, 74: 254-272.

Zheng, W., Singh, K., Chung, C. 2017. Ties to Unbind: Political Ties and Firm Sell-Offs During Institutional Transition. Journal of Management, 43: 2005-2036.

Zimmerman, D. 2008. Understanding the impact of personality traits on individuals' turnover decisions. A meta-analytic path model. Personnel Psychology, 61: 309-348. 
WHEN STAYING IS DISSATISFYING

TABLE 1

Descriptive Statistics and Correlations in Study 1

\begin{tabular}{|c|c|c|c|c|c|c|c|c|c|c|c|c|c|}
\hline Variable & $M$ & $S D$ & 1 & 2 & 3 & 4 & 5 & 6 & 7 & 8 & 9 & 10 & 11 \\
\hline 1.Gender ${ }^{\mathrm{a}}$ & 0.48 & 0.50 & - & & & & & & & & & & \\
\hline 2.Full-time work ${ }^{b}$ & 0.85 & 0.36 & $-.29 * *$ & - & & & & & & & & & \\
\hline 3.Organization $1^{\mathrm{c}}$ & 0.37 & 0.48 & $-.44 * *$ & .06 & - & & & & & & & & \\
\hline 4.Organization $2^{\mathrm{c}}$ & 0.20 & 0.40 & .10 & $.02 *$ & $-.38 * *$ & - & & & & & & & \\
\hline 5.Organization $3^{\mathrm{c}}$ & 0.17 & 0.37 & $.45^{* *}$ & $-.27 * *$ & $-.34 * *$ & $-.22 * *$ & - & & & & & & \\
\hline 6.Turnover cognitions T1 & 1.87 & 0.99 & -.09 & -.04 & $.17^{*}$ & .00 & -.08 & - & & & & & \\
\hline 7.Internal job transition $\mathrm{T} 2^{\mathrm{b}}$ & 0.25 & 0.43 & $-.16^{*}$ & .01 & -.01 & -.08 & $-.18 * *$ & .01 & - & & & & \\
\hline 8.Lack of job opportunities T2 & 6.61 & 1.41 & .06 & $.16^{*}$ & -.09 & .05 & $-.13 *$ & $.15 *$ & .13 & - & & & \\
\hline 9.On-the-job embeddedness $\mathrm{T} 1$ & -0.00 & 0.45 & -.10 & .11 & $-.19 * *$ & $.16^{*}$ & $-.18 * *$ & $-.47 * *$ & -.02 & -.05 & - & & \\
\hline 10.Off-the-job embeddedness $\mathrm{T} 1$ & -0.02 & 0.66 & .11 & -.12 & -.08 & .03 & .07 & $-.18 * *$ & $-.16^{*}$ & $-.24 * *$ & .10 & - & \\
\hline 11.Career satisfaction $\mathrm{T} 1$ & 5.32 & 1.05 & .03 & .02 & $-.32 * *$ & .12 & .05 & $-.51 * *$ & -.09 & -.04 & $.59 * *$ & .09 & - \\
\hline 12. Career satisfaction $\mathrm{T} 2$ & 5.01 & 1.28 & .06 & .13 & $-.33 * *$ & $.16^{*}$ & .11 & $-.45 * *$ & .06 & -.02 & $.45^{* *}$ & -.09 & $.58 * *$ \\
\hline
\end{tabular}

$N=226 .{ }^{\mathrm{a}} 1=$ 'female'; $0=$ 'male'; ${ }^{\mathrm{b}} 1=$ 'yes' and $0=$ 'no'; ' Reference category: organization 4.

$* p<.05$. ** $p<.01$. 
WHEN STAYING IS DISSATISFYING

TABLE 2

Results of Moderated Hierarchical Regression Analyses for Career Satisfaction T2 Regressed on Turnover Cognitions T1, Moderated by Internal Job Transition (Model 1), Lack of External Job Opportunities (Model 2), On-the-Job Embeddedness (Model 3), and Off-the-Job Embeddedness

\section{(Model 4) (Study 1)}

\begin{tabular}{|c|c|c|c|c|c|c|c|c|}
\hline \multirow[b]{2}{*}{ Predictor } & \multicolumn{2}{|c|}{ Model 1} & \multicolumn{2}{|c|}{ Model 2} & \multicolumn{2}{|c|}{ Model 3} & \multicolumn{2}{|c|}{ Model 4} \\
\hline & $\mathrm{B}(S E)$ & $\mathrm{B}(S E)$ & $\mathrm{B}(S E)$ & $\mathrm{B}(S E)$ & $\mathrm{B}(S E)$ & $\mathrm{B}(S E)$ & $\mathrm{B}(S E)$ & $\mathrm{B}(S E)$ \\
\hline Female $^{\mathrm{a}}$ & $-.05(.16)$ & $-.04(.16)$ & $-.11(.17)$ & $-.09(.16)$ & $-.08(.16)$ & $-.09(.16)$ & $-.08(.16)$ & $-.06(.16)$ \\
\hline Full-time contract ${ }^{\mathrm{b}}$ & $.51(.20)^{*}$ & $.54(.20)^{*}$ & $.47(.20)^{*}$ & $.44(.19)^{*}$ & $.46(.20)^{*}$ & $.47(.20)^{*}$ & $.40(.20)^{*}$ & $.34(.19) \dagger$ \\
\hline Organization $1^{\mathrm{c}}$ & $-.59(.20)^{*}$ & $-.55(.20)^{*}$ & $-.61(.20)^{*}$ & $-.67(.20)^{*}$ & $-.55(.20)^{*}$ & $-.55(.20)^{*}$ & $-.62(.20)^{*}$ & $-.64(.20)^{*}$ \\
\hline Organization 2 & $-.37(.20)$ & $-.33(.20) \dagger$ & $-.29(.20)$ & $-.33(.19) \dagger$ & $-.27(.20)$ & $-.26(.20)$ & $-.30(.20)$ & $-.31(.19)$ \\
\hline Organization 3 & $.12(.23)$ & $.13(.23)$ & $.09(.23)$ & $-.04(.23)$ & $.20(.24)$ & $.22(.24)$ & $.07(.23)$ & $.05(.22)$ \\
\hline Career satisfaction T1 & $.53(.08)^{* *}$ & $.54(.08)^{* *}$ & $.50(.08)^{* *}$ & $.52(.08)^{* *}$ & $.43(.09)^{* *}$ & $.43(.09)^{* *}$ & $.50(.08)^{* *}$ & $.48(.08)^{* *}$ \\
\hline Turnover cognitions T1 & $-.26(.08)^{* *}$ & $-.25(.08)^{*}$ & $-.28(.08)^{* *}$ & $-.29(.08)^{* *}$ & $-.23(.08)^{*}$ & $-.25(.09)^{*}$ & $-.31(.08)^{* *}$ & $-.34(.07)^{* *}$ \\
\hline Internal job transition $\mathrm{T} 2^{\mathrm{d}}$ & $.37(.16)^{*}$ & $.37(.16) *$ & - & - & - & - & - & - \\
\hline Lack of external job opportunities T2 & - & - & $.00(.05)$ & $-.05(.05)$ & - & - & - & - \\
\hline On-the-job embeddedness T1 & - & - & - & - & $.39(.20)^{*}$ & $.40(.20)^{*}$ & - & - \\
\hline Off-the-job embeddedness T1 & - & - & - & - & - & - & $-.33(.10)^{*}$ & $-.36(.10)^{* *}$ \\
\hline $\mathrm{TC}^{\mathrm{e}} \mathrm{x}$ Internal job transition & - & $.28(.16) \dagger$ & - & - & - & - & - & - \\
\hline $\mathrm{TC}^{\mathrm{e}} \mathrm{x}$ Lack of external job opportunities & - & - & - & $.17(.04)^{* *}$ & - & - & - & - \\
\hline $\mathrm{TC}^{\mathrm{e}} \mathrm{x}$ On-the-job embeddedness & - & - & - & - & - & $-.11(.14)$ & - & - \\
\hline $\mathrm{TC}^{\mathrm{e}} \mathrm{x}$ Off-the-job embeddedness & - & - & - & - & - & - & - & $-.27(.10)^{* *}$ \\
\hline $\mathrm{R}^{2}$ & $.428 * *$ & $.436^{* *}$ & $.414 * *$ & $.457 * *$ & $.424 * *$ & $.426 * *$ & $.441 * *$ & $.458 * *$ \\
\hline Change in $\mathrm{R}^{2}$ & $.047 * * \mathrm{f}$ & $.008 \dagger$ & $.033 * \mathrm{f}$ & $.043^{* *}$ & $.043 * * \mathrm{f}$ & .002 & $.060 * * \mathrm{f}$ & $.017 * *$ \\
\hline
\end{tabular}

$N=226 .{ }^{\text {a }}$ Reference category: male; ${ }^{\mathrm{b}}$ Reference category: part-time contract; ${ }^{\mathrm{c}}$ Reference category: organization 4 ; ${ }^{\mathrm{d}}$ Reference category: not made an internal job transition; ${ }^{\mathrm{e}} \mathrm{TC}=$ turnover cognitions. ${ }^{\mathrm{f}}$ The change in $\mathrm{R}^{2}$ reported here is the difference between the $\mathrm{R}^{2}$ of this model with the $\mathrm{R}^{2}$ of a model with only the control variables, which had an $\mathrm{R}^{2}$ of .381 .

$\dagger p<.10 ; * p<.05 . * * p<.01$. 
Running Head: DO TURNOVER COGNITIONS AFFECT STAYERS?

TABLE 3

Comparison of Fit Indices between Six-Factor Model, Five-Factor Model, Three-Factor Model and Single-Factor Model (Study 2)

\begin{tabular}{llllll}
\hline Model & $\mathrm{X}^{2}[\mathrm{df}]$ & RMSR & RMSEA [90\% CI $]$ & CFI & $\Delta \mathrm{X}^{2}[\mathrm{df}]^{\mathrm{a}}$ \\
\hline Six-factor model & $374.81[174]$ & .03 & $.04[.03 ; .05]$ & .98 & \\
Five-factor model & $567.84[179]$ & .04 & $.06[.05 ; .06]$ & .97 & $193.03[5]^{* *}$ \\
Three-factor model & $3634.81[186]$ & .12 & $.16[.16 ; .17]$ & .69 & $3260.00[12]^{* *}$ \\
Single-factor model & $5261.11[189]$ & .13 & $.20[.19 ; .20]$ & .55 & $4886.30[15]^{* *}$ \\
\hline${ }^{\text {a }}$ Chi square difference test comparing the fit of this model with the fit of the six-factor model. \\
$* * p<.01$
\end{tabular}

TABLE 4

Descriptive Statistics and Correlations among Key Variables in Study 2

\begin{tabular}{|c|c|c|c|c|c|c|c|}
\hline Variable & $M$ & $S D$ & 1 & 2 & 3 & 4 & 5 \\
\hline 1. Turnover cognitions $\mathrm{T} 1$ & 2.04 & 1.14 & - & & & & \\
\hline 2. Turnover cognitions T3 & 2.18 & 1.21 & $.65^{* *}$ & - & & & \\
\hline 3. Regret T2 & 1.93 & 1.06 & $.49 * *$ & $.41 * *$ & - & & \\
\hline 4. Justifiability $\mathrm{T} 2$ & 4.02 & 1.05 & $-.22 * *$ & $-.22 * *$ & $-.43 * *$ & - & \\
\hline 5. Career satisfaction $\mathrm{T} 1$ & 3.55 & 0.79 & $-.44 * *$ & $-.37 * *$ & $-.40 * *$ & $.26^{* *}$ & - \\
\hline 6. Career satisfaction T3 & 3.50 & 0.76 & $-.38 * *$ &.$-.42 * *$ & $-.41 * *$ & $.31 * *$ & $.70 * *$ \\
\hline
\end{tabular}


WHEN STAYING IS DISSATISFYING

\section{FIGURE 1}

Relationship between turnover cognitions and career satisfaction for stayers who made or did not make an internal job transition (upper panel), with many or few external job opportunities (middle panel), and who were little or highly embedded in their community (lower panel).

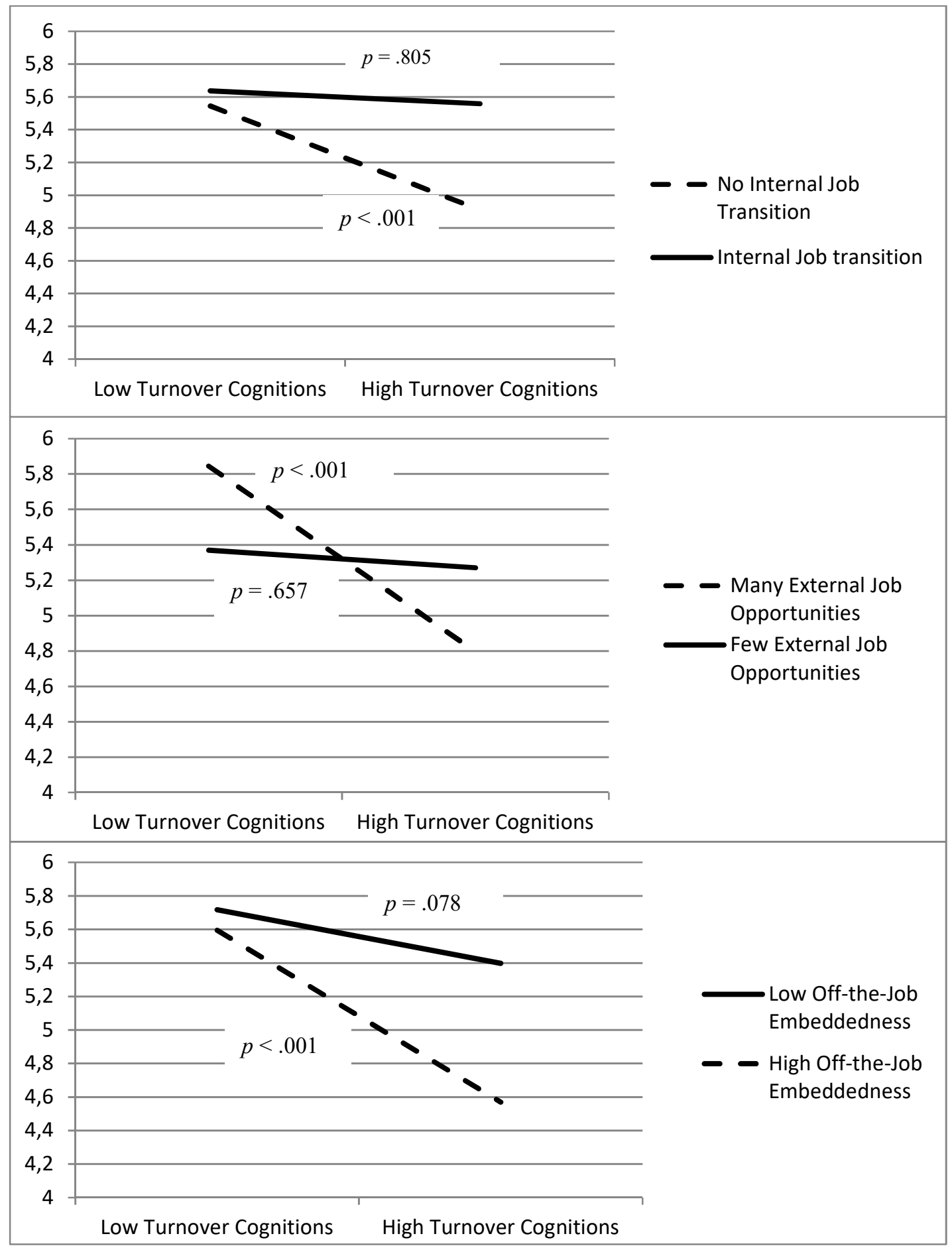

Note: Reported $p$-values are the $\mathrm{p}$-values of the simple slope tests (2-tailed) for internal job transition at values 0 and 1 (upper panel), for external job opportunities at -1 SD and $+1 \mathrm{SD}$ (middle panel) and for off-the-job embeddedness at - 1SD and + 1SD (lower panel). 
WHEN STAYING IS DISSATISFYING

FIGURE 2

Results of the Cross-Lagged Panel Model in Study 2 (unstandardized regression coefficients)

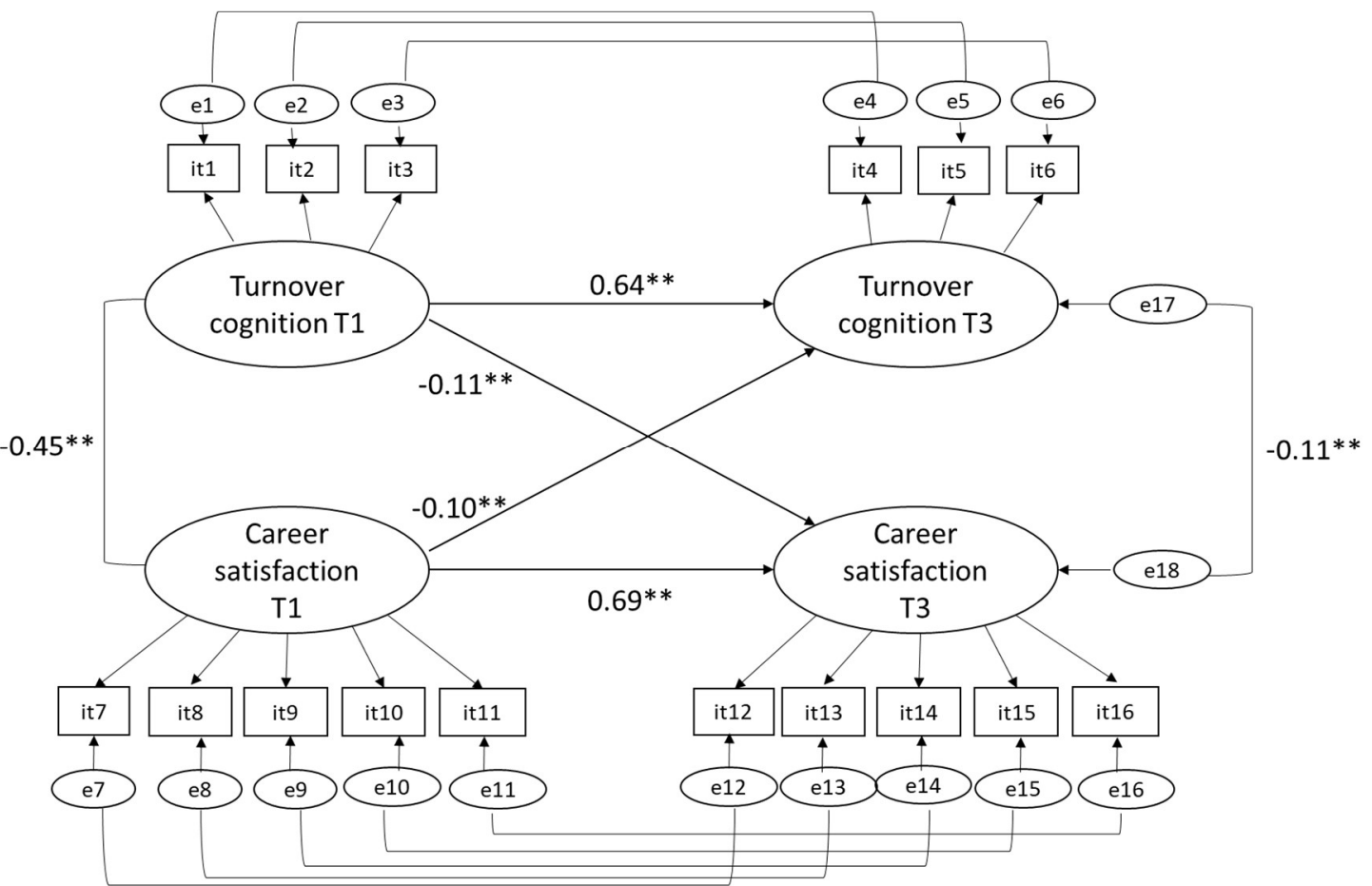

$* * p<.01$

FIGURE 3

Results of the Structural Mediation Model in Study 2 (unstandardized regression coefficients)

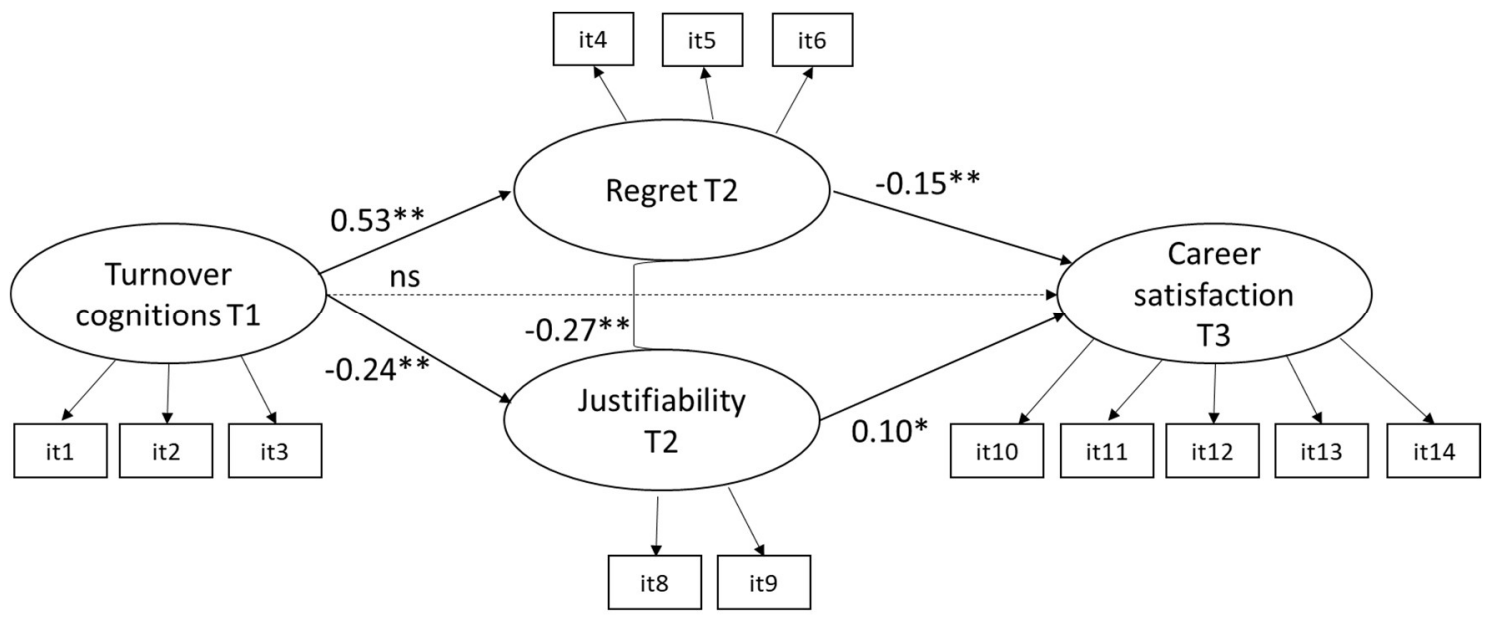

$* p<.05$

$* * p<.01$ 
WHEN STAYING IS DISSATISFYING

APPENDIX: The Off-The-Job-Embeddedness Items Included in Study 1

Fit (3 of the original 5 items)

1. I really love the place where I live

2. This community is a good match for me

3. I think of the community where I live as home

Links ( 3 of the original 6 items)

4. Are you currently married?

5. How many family members live nearby?

6. How many of your close friends live nearby?

Sacrifices (3 of the original 3 items)

7. Leaving this community would be very hard

8. People respect me a lot in my community

9. My neighborhood is safe 